Cipango Cahiers d'études japonaises

$21 \mid 2014$

Nouveaux regards sur les arts de la scène japonais II

\title{
Une histoire du striptease japonais
}

A history of Japanese striptease

\section{Éric Dumont et Vincent Manigot}

\section{(2) OpenEdition}

\section{Journals}

\section{Édition électronique}

URL : https://journals.openedition.org/cipango/2230

DOI : $10.4000 /$ cipango. 2230

ISSN : 2260-7706

Éditeur

INALCO

Édition imprimée

Date de publication : 31 décembre 2014

ISSN : 1164-5857

\section{Référence électronique}

Éric Dumont et Vincent Manigot, « Une histoire du striptease japonais », Cipango [En ligne], 21 | 2014, mis en ligne le 26 septembre 2016, consulté le 30 juin 2021. URL : http://journals.openedition.org/ cipango/2230 ; DOI : https://doi.org/10.4000/cipango.2230

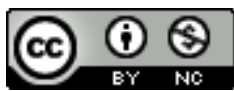

Cipango est mis à disposition selon les termes de la Licence Creative Commons Attribution - Pas d'Utilisation Commerciale 4.0 International. 


\title{
Une histoire du striptease japonais
}

$A$ history of Japanese striptease

\author{
Éric Dumont \\ Université de Genève \\ Vincent Manigot \\ CEJ, Inalco, Tōkyō University of Foreign Studies
}

Note de la rédaction : nous adressons nos chaleureux remerciements à Hara Yoshiichi 原芳 市, Moriyama Daidō 森山大道 et Moriyama Sōhey 森山想平, ainsi qu’à la succession de Hirooka Keiichi 広岡敬一 d'avoir accepté que soient gracieusement reproduites les photos qui illustrent cet article.

En apparence, définir l'effeuillage ne semble poser aucun problème : spectacle de déshabillage à visée érotique. Une danseuse se dévêt en public. Sur scène peu à peu, elle met son corps à nu. À sa vue, le regard des spectateurs s'excite, réjoui pour certains, désabusé, voire outré, pour d'autres. La distribution des genres est pour ainsi dire intuitivement soufflée par l'expérience que nous faisons au quotidien d'une société phallocrate et de la place qu'y occupe le corps féminin dans l'imaginaire érotique. De problématique, il n'y aurait ainsi que le regard porté sur la chose : est-ce de l'art ? La question renvoie à la posture normative adoptée face à ce que nous nommons, par commodité, la « pornographie ». 


\section{CIPANGO}

134 Cahiers d'études japonaises n²1

Pour ou contre, et surtout, jusqu'à quel point ? Ainsi, à supposer qu'elle présente quelque intérêt, l'étude du striptease révélerait avant tout l'attitude d'une société donnée, permissive ou intolérante, en matière de mœurs érotiques. Nous pensons néanmoins qu'une histoire des formes n’est pas dénuée de pertinence. En dépit des idées reçues, les formes apparaissent bien plus fluctuantes qu'il n'y paraît. Si l'évolution des formes est profondément liée à celle des mœurs, donc aux changements de perception du striptease, il nous semble que l'inventivité croissante des spectacles d'effeuillage suffit à en faire un objet d'étude valable sur le plan artistique également.

Nous pouvons à bon droit estimer qu'il y eut dévêtement dès qu'il y eut des vêtements. Le Kojiki rapporte qu'au temps des dieux déjà, Ame no Uzume 天宇 受賣 au cours d'une danse se dénuda, provoquant l'hilarité générale au sein de l'assemblée et incitant de ce fait la déesse du soleil à quitter sa retraite. Pourtant, considérer Ame no Uzume comme une pionnière du striptease, dans l'archipel comme dans le monde, serait bien évidemment anachronique.

Le terme même de «striptease » apparaît sans doute au début des années 1930, un peu avant selon certaines sources ${ }^{1}$. Des spectacles érotiques qui rétrospectivement pourraient se voir qualifier de la sorte ont sans doute existé précédemment. L'affaire est cependant fort peu documentée, au Japon comme ailleurs. Si le striptease a certainement une préhistoire, nous avons préféré dans cet article nous concentrer sur son histoire, et éviter ainsi d'éventuelles confusions généalogiques ${ }^{2}$. Le début de l'histoire du striptease est marqué par l'affirmation de son caractère public, c'est-à-dire non réservé à quelque cercle étroit d'initiés. C'est l'apparition de spectacles d'effeuillage affichés et de salles plus ou moins spécialisées dont l'accès, moyennant paiement, est en principe ouvert à tous, qui marque à nos yeux

1. Rachel ShteIr, Striptease: The Untold History of the Girlie Show, New York, Oxford University Press, 2004, p. 90-91. Le Merriam-Webster Dictionary avance la date de 1932.

2. Au Japon, l'histoire du striptease est évidemment solidaire de celles du music-hall, de l'opéra-Asakusa et du théâtre populaire. Voir Ōzasa Yoshio 大笹吉雄, «Sannin no dansā ni yoru odoriko tsūshi »三人のダンサーによる踊り子通史 (Histoire générale des danseuses en trois danseuses), in Inoue Hisashi 井上ひさし, Asakusa Furansu-za no jikan 浅草フランス座の時間 (Au temps de l'Asakusa Furansu-za), Tōkyō, Bunshun nesuko 文春ネスコ, 2001, p. 99-125. Voir aussi Jean-Jacques TschUdIN, « L’OpéraAsakusa : le drame lyrique à la conquête du public populaire », in Jean-Jacques TsCHUDIN, Claude Hamon (dir.), La Modernité à l'horizon, Arles, Philippe Picquier, 2004, p. 169-190. 
l'avènement du striptease. En ce sens, l'origine des spectacles d'effeuillage est à faire remonter à la fin du $\mathrm{XIX}^{\mathrm{e}}$ siècle, où le striptease se développe pour la première fois dans sa forme instituée, théâtralisée, et surtout accessible au plus grand nombre. Il est peu fécond ici d'arrêter une date ou de fixer un évènement actant de sa naissance, mais l'on peut affirmer que le striptease voit le jour de manière assez proche en France et aux États-Unis, au sein de spectacles de cabaret ${ }^{3}$. Au Japon, il n'apparaîtra qu'après la Seconde Guerre mondiale ${ }^{4}$, et prendra bientôt des formes si diverses qu'il serait bien mal aisé d'en arrêter une définition unique et définitive. En effet, le terme de «striptease » renvoie aussi bien à un ensemble de techniques, un type de numéros, un genre de spectacles, qu'à des conditions matérielles situées, des lieux, des personnes, des professions, etc. Les pratiques et éléments concernés dépassent par conséquent le « déshabillage sur scène », dont les manifestations formelles demandent dès lors à être décrites et problématisées.

Apparu au lendemain de la guerre, le striptease a connu au Japon diverses évolutions jusque dans les années 1970. Le présent travail propose de retracer ces évolutions, que nous avons réparties sur trois périodes : en premier lieu, l'apparition

3. Si les sources peinent à s'accorder sur une date, il est vraisemblable que les premiers spectacles de ce type sont apparus en France dans les années 1880-1890, un peu plus tard aux États-Unis ; François Des Aulnoyes, Histoire et philosophie du striptease : essai sur l'érotisme au music-hall, Paris, Pensée moderne, 1957, p. 28 ; Richard Wortley, $A$ Pictorial History of Striptease, London, Octopus, 1976, p. 31 et 55-56; Don B. Wilmeth, The Cambridge Guide to American Theater, Cambridge, Cambridge University Press, 2007, p. 487. Il est probable qu'il y eût des précédents, cependant la performance d'une certaine Mona (ou Manon) lors du «Bal des Quat'z-Arts », le 9 février 1893 au Moulin Rouge, fit grand bruit et est souvent présentée comme l'acte de naissance des spectacles d'effeuillage ; Martin Banham, The Cambridge Guide to Theater, Cambridge, Cambridge University Press, 1995, p. 802 ; voir l'article qui lui est consacré dans Le Matin du 21 mars 1893, et le compte-rendu du procès pour « outrage public à la pudeur » dans le même quotidien, le 24 juin 1893 (voir bibliographie).

4. Voir notamment Ozawa Shōichi 小沢昭一, FukaI Toshihiko 深井俊彦, Nakatani Akira 中谷陽, 《Kieru hi, Moeru honō - Sengo sutorippu-shi » 消える 灯 燃える炎一戦後ストリップ史 (La lumière s'éteint, la flamme brûle : histoire du striptease de l'après-guerre), Shingeki - tokushū sutorippu 新劇一特集ス卜リッ プ (Shingeki : numéro spécial sur le striptease), nº 9, Tōkyō, Hakusuisha 白水社, 1973, p. 94-109. C'est en 1950 que l'Asahi shinbun traite pour la première fois du striptease dans son édition matinale du 18 juin 1950, p. 4. 


\section{CIPANGO}

136 Cahiers d'études japonaises n²1

du striptease au lendemain de la guerre, période de profonds bouleversements, et la conquête du mouvement; puis la transition vers un modèle théâtral à la charnière des années 1950, qu'accompagne la création de salles spécialisées où le striptease se danse ; enfin, les diverses mutations qu'il connaîtra durant les années 1960, où le plaisir se joue. De cette périodisation schématique, on se gardera de conclure que les années 1970 sonnent le glas de l'histoire du striptease. En effet, des spectacles sont de nos jours encore donnés au sein de salles spécialisées ${ }^{5}$. Nous avançons toutefois l'idée que l'évolution formelle du striptease a, pour le moment du moins, atteint ses limites à l'aube des années 1970, pour ne plus connaître, depuis, d'évolution notoire.

Des données statistiques concernant le nombre de salles, leur propriétaire, leur taux de fréquentation ainsi que les revenus engrangés seraient sans doute riches d'enseignements ; malheureusement, il nous a été impossible de nous procurer des chiffres fiables. Le caractère interlope de ce type d'industrie ne contribue pas à la production et encore moins à la publication officielle de tels documents. Des chiffres relatifs aux danseuses - tels que revenu moyen, espérance de vie, durée de leur carrière - auraient été du plus grand intérêt. Mais là encore, et à l'exception de quelques mentions discrètes ${ }^{6}$ et biographies tendant parfois à l'hagiographie, nous ne sommes pas parvenus à obtenir des données suffisantes pour autoriser une généralisation.

À propos de ces chiffres, de leur absence plutôt, nous pouvons formuler plusieurs hypothèses. Premièrement, le striptease n'a peut-être pas encore véritablement retenu l'attention de chercheurs en sciences sociales. Deuxièmement,

5. Ainsi pour Tōkyō l’Asakusa Rokku-za 浅草ロック座 (Rock-za d'Asakusa), le Shiatā Ueno シアタ一上野 (Theater Ueno) et quelques autres salles sont toujours actives.

6. SATō Makoto 佐藤信 affirme par exemple avoir vu se produire une stripteaseuse âgée de soixante-trois ans, dans «Gankyū shaburi - Odoriko-ron nōto » 眼球しゃ ぶり一踊り子論ノ一ト (Léchage de globes oculaires : notes pour une théorie de la danseuse), Shingeki - tokushū sutorippu 新劇一特集ストリップ,op. cit., 1973, p. 56. Le photographe Hara Yoshiichi 原芳市 nous confia également qu’une danseuse âgée de soixante-neuf ans se produirait aujourd'hui encore dans un théâtre-striptease de Yokohama, le Ōgon gekijō 黄金劇場. Celui-ci semble cependant avoir fermé ses portes en 2012. 
nombre de danseuses changèrent de noms à maintes reprises et la nature du monde dans lequel elles évoluaient (ou évoluent encore) ne favorise pas la transparence de l'information. Troisièmement, nous pouvons penser qu'après avoir tourné le dos à la scène, nombre de danseuses rejoignirent tout simplement la masse des citoyennes «standards », retournant à l'anonymat. Faute de documents, il ne nous est pas possible de discuter de manière satisfaisante des conditions de vie des effeuilleuses en général. Nous proposons donc ici l'histoire d'un art de la scène qui ne nous semble pas réductible à des données chiffrées, en ayant conscience des limites que cela impose à notre propos. Nous le verrons : nombre d'artistes, dont la renommée a pour certains largement débordé les frontières de l'archipel, entretiennent des liens profonds avec le monde de l'effeuillage. Indépendamment des grands noms qui gravitèrent autour du striptease et en dépit de son caractère d'art vulgaire - au sens de populaire - ce genre compte indéniablement parmi les premières formes théâtrales à questionner la dynamique des corps dans l'aprèsguerre japonais, bien avant les ballets de Jikken kōbō 実験工房 ou le butō 舞踏 de Hijikata Tatsumi 土方巽. Ce dernier s'intéressera d'ailleurs de près au striptease, dont il chorégraphiera des spectacles durant les années $1960^{7}$. De manière générale, le striptease est sans cesse confronté à des problèmes très concrets de mise en scène et d'autres, moins techniques, de désir et d'érotisme. L'histoire du striptease nous renseigne donc aussi bien sur celle des mœurs, que sur celle des arts de la scène, au sens propre.

\section{Les débuts du striptease au Japon (1945-1948)}

\section{Un nouvel usage du corps : le tableau vivant}

La période de l'immédiat après-guerre japonais voit l'apparition rapide et massive de formes artistiques faisant un usage nouveau du corps, posant de nouvelles ques-

7. Voir The Tsubouchi Memorial Theater Museum Digital Archives Collection. 


\section{CIPANGO}

138 Cahiers d'études japonaises n²1

tions quant à la corporéité, bien loin de l'hygiénisme qui primait jusqu'en $1945^{\circ}$. Avec les Américains arrive toute une culture populaire, dont les revues appelées kasutori zasshi カストリ雑誌 sont la parfaite illustration ${ }^{9}$. Ces dernières trouvent leur modèle dans les pulps qui existent déjà depuis de nombreuses années aux États-Unis. Dans le but - non avoué - d'augmenter ses ventes, le magazine Life avait ainsi en 1937 fait scandale en publiant un article qui allait devenir un modèle à suivre pour tous ses concurrents. « How to Undress for Your Husband » proposait un véritable cours d'effeuillage à l'attention de la ménagère soucieuse

8. Nous ne cherchons pas à nier l'existence d'un matériel graphique suggestif voire explicite avant 1945. Les photographies, qu'une sensibilité actuelle rechignerait peu à taxer de «pornographiques », remontent ainsi pour les plus anciennes à l'ère Meiji ; SHImokawa Kōshi 下川耿史, Nihon eroshashin-shi 日本工口写真史 (Histoire de la photo érotique japonaise), Tōkyō, Chikuma bunko ちくま文庫, 2003. Nous postulons toutefois une différence d'échelle considérable avec l'après-guerre.

9. Du nom d'un alcool de qualité variable - au mieux médiocre - le kasutori shōchū 力 ストリ焼酎, répandu au lendemain de la guerre. Son fort degré d'alcool et les produits dangereux avec lesquels il était parfois mélangé, étaient réputés pour provoquer une perte de connaissance si sa consommation dépassait les trois verres (san gō 三合). Nombre de ces publications ne dépassèrent pas le troisième numéro (san gō 三号), d'où, par homophonie, l'appellation de kasutori zasshi. On estime que dans les deux années qui suivirent l'apparition du genre (1946), plus de sept cents revues érotiques virent le jour. Voir à ce sujet : Shōwa nimannichi no zenkiroku, Dai 7 kan - Haikyo kara no shuppatsu, Shōwa 20 nen-21 nen 昭和二万日の全記録・第7巻－廃墟からの出発・昭和 20 年 ～21年 (Chroniques des 20000 jours de l'ère Shōwa, tome $7:$ le départ à partir des ruines, années 1945-1946), Tōkyō, Kōdansha 講談社, 1989, p. 192 et 275, (plus loin : SNNZ); John W. Dower, Embracing Defeat: Japan in the Wake of World War II, New York, W.W. Norton \& Co. - The New Press, 1999, p. 148 et suivantes ; Mark McLelland, “Kissing is a Symbol of Democracy!' Dating, Democracy, and Romance in Occupied Japan, 19451952", Journal of the History of Sexuality, vol. 19, n 3, Austin, University of Texas Press, 2010, p. 523 ; Kашамото Kōji 川本耕次, Poruno zasshi no shōwa-shi ポル/雑誌の 昭和史 (Histoire de l'ère Shōwa par les magazines pornographiques), Tōkyō, Chikuma shobō 筑摩書房, «Chikuma shinsho » 筑摩新書, 2011, p. 12-16. 
de charmer son tendre époux ${ }^{10}$. Sur le modèle de ces magazines américains, les couvertures des kasutori zasshi présentent régulièrement des femmes sensuelles. Dès 1946, le magazine Aka to kuro 赤と黒 (Le rouge et le noir) publie la photo d'une femme à moitié nue ${ }^{11} .1946$ est également l'année du premier baiser dans le cinéma japonais, qui inaugure ce que l'on ne tardera pas à appeler les seppun eiga 接吻映画 (films de baisers) ${ }^{12}$. L'année suivante, dessins ou peintures de femmes nues - ou semi-nues - deviennent monnaie courante dans ces publications. En fait, et ce tout particulièrement aux États-Unis mais également en France, le photojournalisme et les pulps ne font que s'engouffrer dans une brèche déjà ouverte par les films hollywoodiens, les bains de soleil dont la popularité est croissante, ou encore les concours de beauté, qui tous banalisent certains aspects de la nudité. Le Japon prendra un chemin analogue : en 1947 est ainsi lancée l'élection de Miss Ginza, premier concours de beauté à l'occidentale du Japon.

Toutefois, 1947 est surtout l'année de baptême de ce qu'il conviendra plus tard d'appeler «striptease ». Début janvier, dans une petite salle située au cinquième étage du Teito-za 帝都座, théâtre alors affilié au groupe Tōhō, les spectateurs peuvent assister, moyennant vingt yens, à un spectacle d'un genre nou-

10. L'analogie de ce type de séries photographiques avec le striptease est intéressante : beaucoup d'autres suivront, dans Life notamment, introduisant nombre des schémas que l'on retrouve dans le striptease, tels les scènes de bain, de déshabillage, mais aussi les tenues affriolantes et les postures suggestives. On se souviendra que le magazine Playboy apparaît en 1953 ; Dolores Flamiano, "The (Nearly) Naked Truth: Gender, Race, and Nudity in Life, 1937", Journalism History, vol. 28, $\mathrm{n}^{\circ}$ 3, Northridge (CA), Journalism Dept. of California State University, 2002, p. 121-136.

11. John W. Dower, op. cit., 1999, p. 149.

12. Il s'agit du film Hatachi no seishun はたちの青春 (La jeunesse à vingt ans) de Sasaki Yasushi, qui fit grand bruit à l'époque. Voir notamment $S N N Z$, vol. 7, p. 257 ; Mark McLelland, op. cit., 2010, p. 530 ; Tsurumi Shunsuke 鶴見俊輔, SATŌ Tadao 佐藤忠男, KITA Morio 北杜夫 (dir.), Manga sengoshi 漫画戦後史(Histoire des mangas de l'après-guerre), n ${ }^{\circ}$, Tōkyō, Chikuma Shobō 筑摩書房, «Gendai manga » 現代漫 画, 1970, p. 46. Il est intéressant de constater que l'apparition du baiser au cinéma et la naissance du striptease moderne sont concomitantes, au Japon comme aux États-Unis : en 1896 déjà, soit l'année suivant la présentation par les frères Lumière de leur invention, l'Américain William Heise proposait au public le bien nommé The Kiss. 


\section{CIPANGO}

veau : le gakubuchi nūdo shō 額縁 ヌードショー (spectacle de nu encadré ${ }^{13}$ ), durant lequel une jeune fille plus court-vêtue que véritablement dénudée pose au sein d'une composition, tendant à créer une sorte de tableau vivant. La poitrine pudiquement recouverte, Nakamura Emiko 中村笑子 figure ainsi la Vénus de Botticelli. La revue emprunte du reste son titre à l'œuvre : Vinasu no tanjōヴィー ナスの誕生 (La naissance de Vénus), suggérant par là l'importance que la production accordait à ce numéro. Notons aussi que le fait que le choix se soit porté sur La naissance de Vénus fait de manière bien singulière le pont entre l'érotisme de la Renaissance et les spectacles de nu à venir ${ }^{14}$. À y mieux regarder, la filiation entre le striptease des premières heures et l'art classique - par l'intermédiaire des tableaux vivants notamment - est en fait assez évidente. Au-delà du cadre entourant celle qui n'est pas encore une effeuilleuse, c'est peut-être l'absence sur scène de l'homme qui fait le lien entre les deux formes artistiques. L'absence de l'homme, tout comme la nudité de la femme, n'est en fait pas complète, puisque sa présence est suggérée ; celui-ci est présent par le biais de l'imagination. À propos des œuvres de la Renaissance - mais la réflexion peut aisément s'appliquer aux spectacles de striptease - l'historienne de l'art Daniela Hammer-Tugendhat précise :

Cela peut paraître incroyable, mais l'art a réussi un vrai tour de force : rendre l'homme complètement invisible dans l'acte sexuel. À la renaissance, quand on représente l'acte sexuel, ce qui est rare, c'est toujours en s'inspirant des métamorphoses d'Ovide. Ce poème évoque toute une série de mythes dans lesquels un dieu, en l'occurrence le roi des dieux Zeus, a des rapports avec une mortelle.

13. La jeune fille est littéralement « encadrée », au même titre qu'un tableau peut l'être. Elle évolue dans l'espace habituellement dévolu à la toile du peintre et est présentée comme derrière une fenêtre.

14. Les gakubuchi nüdo shō peuvent être à rapprocher des tableaux vivants qui furent notamment utilisés dans le Paris du XvinIe siècle pour rendre plus intense la présentation d'actes sexuels dans des pièces grivoises (il ne s'agit pas ici de striptease); Laurence Senelick, "The Word Made Flesh: Staging Pornography in EighteenthCentury Paris", Theatre Research International, vol. 33, n² 2, Cambridge, U.K., Cambridge University Press, 2008, p. 191-203. 
Et pour ce faire, il se métamorphose systématiquement. Avec Danaé, il se transforme en pluie d'or ; avec Io, en nuage ; avec Léda, en cygne ; avec Europe, en taureau. Bref, tout ce qu'on peut imaginer, mais il n'est jamais lui-même. Dans l'art, ça veut dire qu'on a affaire à un acte sexuel, c'est même le thème principal de l'œuvre, mais qu'on ne voit en fait qu'un nu féminin, car l'homme disparaît dans la métamorphose. La femme incarne en quelque sorte la sexualité et la matérialité du corps, tandis que l'homme est associé au spirituel ${ }^{15}$.

À l'origine du gakubuchi nūdo se trouve Hata Toyokichi 秦豊吉 (1892-1956). Diplômé de l'université impériale de Tōkyō, il séjourne à Berlin entre 1917 et 1926 pour le compte de la compagnie Mitsubishi. De retour au Japon, il quitte son poste et intègre le Tōkyō Takarazuka gekijō 東京宝塚劇場 dont il devient directeur en $1940^{16}$. Après la défaite, Hata reste en poste à la Tōhō. Malgré quelques difficultés, l'occupation se présente à lui comme une opportunité de réaliser un projet de longue date : un spectacle inspiré par le modèle du musical à l'américaine, mais aussi par ses souvenirs des cabarets berlinois de 1918. La naissance de Vénus est donc composée de plusieurs parties : danses, chants, tours de passepasse, sketches, sans oublier la touche érotique, le gakubuchi nüdo. Ce dernier ne durait en réalité que quelques dizaines de secondes, le temps pour les spectateurs de remarquer que le «tableau » respirait. Que les critiques de l'époque se soient focalisées sur cette partie, au point d'oublier de mentionner le reste du spectacle, laisse imaginer l'impact considérable que produisit l'arrivée du nūdo ヌード (le nu) sur les scènes, en plus d'anticiper, en quelque sorte, la place prépondérante qu'il s'apprêtait à prendre.

Dès le mois de février 1947, Kai Miwa 甲斐美和, danseuse âgée de dix-neuf ans, remplace Nakamura sur les planches du Teito-za, et se dévêt cette fois complètement au-dessus de la taille dans Ru Panteon ル・パンテオン (Le

15. Herbert Eisenschenk (réalisateur), Le Nu absolu [film documentaire], Autriche France, Arte - Vermeer Film/ORF, 2010, 29-30 min.

16. SNNZ, vol. 8, p. 38-39. 


\section{CIPANGO}

142 Cahiers d'études japonaises n²1

Panthéon), augmentant encore le succès déjà important de l'entreprise ${ }^{17}$ qui se prolongera jusqu’à l'année suivante. Le critique Hashimoto Yoshio 橋本与志夫 s'en souviendra en ces termes :

C'était un tableau au sein d'une revue chorégraphiée par Masuda Takashi. Lorsque le rideau se leva, un projecteur bleu cobalt éclairait un pan de la scène au centre de laquelle une danseuse posait à l'intérieur d'un grand cadre.

Ce corps joliment proportionné, les hanches à peine couvertes d'une étoffe fine et la poitrine plantureuse généreusement offerte à la vue, était éclairé par une lumière rose qui, se fondant dans le cobalt de l'arrière-plan, créait une ombre vert clair s'étendant de la poitrine à l'abdomen.

Devant cette beauté, la salle resta quelques instants interdite.

Cet intervalle avait-il à peine duré quatorze ou quinze secondes ? Quatre ou cinq secondes pour certains, trente pour d'autres, la scène s'assombrit en un rien de temps.

益田隆振り付けによるレビューの中の一景だった。幕 があがると、コバルトブルーのライトが舞台一面を照ら し、中央の大きな額縁の中で踊り子がポーズをとつてい る。

わずかに腰のあたりを薄ものでおおつただけで、豊満な 乳房をおしげもなくさらした均整のとれた裸体にピンク の照明があたって、バックのコバルトにとけ、乳房から 腹部にかけて淡いグリーンの翳をつくつていた。

その美しさに一瞬客席は静まりかえつた。

この間、わずか十四、五秒もあつたろうか。四、五秒と いう人から三十秒はあつたという人までいるが、それこ そあつという間に舞台を暗転した ${ }^{18}$ 。

17. Il semble que plusieurs centaines de personnes se pressaient chaque jour devant les guichets pour assister au spectacle; $S N N Z$, vol. 8, p. 38 .

18. Cité dans ŌzasA Yoshio 大笹吉雄, Nihon gendai engeki-shi - Shōwa sengo-hen 日 本現代演劇史一昭和戦後篇 (Histoire du théâtre contemporain au Japon : la période Shōwa après-guerre), vol. 1, Tōkyō, Hakusuisha 白水社, 1998, p. 337-338. 
À noter qu'il s'agit pour lors d'une nudité certes frontale, mais surtout immobile et donc décente. L'immobilité fut d'ailleurs, dans de nombreux pays, un passage obligé vers le nu en mouvement ${ }^{19}$. Le tableau vivant tire en effet toute sa légitimité des modèles illustres qu'il entend figurer. L'immobilité du modèle constitue une condition nécessaire au succès de l'imitation, ainsi qu'un rempart efficace contre une éventuelle censure. Cette stratégie se révéla payante, en ce sens que le GHQ délivra des autorisations pour la représentation de «tableaux ${ }^{20}$ », mais également du fait que les théâtres en vinrent à présenter de plus en plus de nus ${ }^{21}$.

\section{En quête du mouvement}

Le principal problème auquel fait face le striptease à cette époque réside donc dans la contrainte d'immobilité. Nul ne songe, pour le moment, à dévêtir complètement la danseuse. La lingerie peut alors être interprétée comme signe de la nudité. En d'autres termes, les nus portaient des sous-vêtements. Cependant, l'intérêt que présente une

19. François Des Aulnoyes, op. cit., 1957, p. 30-31 ; A. Owen Aldridge, "American Burlesque at Home and Abroad: Together with the Etymology of Go-Go Girl", The Journal of Popular Culture, vol. 5, Issue 3, Bowling Green, Bowling Green State University, 1971 , p. 572.

20. Il est intéressant de constater que, sur ce point, les forces d'occupations n'entendaient pas intervenir. En ce qui concerne la presse, le Press Code for Japan de 1945 précise que ne sont considérés comme prohibés que trois types de publication : toute critique des Alliés; toute forme de propagande ; toute référence à des problèmes du quotidien (alimentation, etc.). L'obscénité (propos d'ordre salace ou immoral par exemple) dans la presse comme ailleurs n'en fait pas partie, et leur interprétation - ainsi que toute censure sur ce point est laissée aux forces de police japonaises. Toutefois, les forces d'occupation ne toléraient aucune référence à la « fraternisation » entre soldats américains et femmes japonaises, ou tout propos laissant supposer une morale douteuse des femmes américaines. Fut ainsi interdite en 1949 la publication d'une revue présentant deux femmes blanches nues, pour cause de « critique des forces alliées »; Mark McLelland, op. cit., 2010, p. 521-522.

21. Le cas de figure fut proche dans l'Angleterre des années 1930. Lord Chamberlain donna son accord aux tableaux qu'il considérait pouvoir être aussi artistiques que les peintures classiques, sous réserve qu'ils demeurent, à l'image des « véritables » tableaux, parfaitement immobiles; ibid., p. 571-572. 


\section{CIPANGO}

144 Cahiers d'études japonaises n²1

danseuse de chair et d'os sur scène par rapport à la femme d'un tableau passe nécessairement par le souffle, la vie, et une certaine forme de mouvement donc. Ainsi, les modèles avaient-elles pour consigne de respirer de manière ostentatoire, en insistant le plus possible sur le ventre et les épaules, tout en restant figées. L'une des solutions les plus inventives fut apportée par Masakuni Otsuhiko 正邦乙彦 qui, cherchant un moyen pour que la danseuse «bouge sans bouger », créa le buranko shō ブラン コ・ショー, le « spectacle à la balançoire » : une danseuse prend place dans un cadre, installé lui-même sur une sorte de grande balançoire qu'une tierce personne fait bouger ; la jeune fille évolue donc dans l'espace tout en demeurant immobile ${ }^{22}$. Notons au passage que dans ces conditions, le métier de stripteaseuse consiste plus à plaire physiquement au spectateur qu’à le charmer véritablement. Danse et effeuillage se côtoient sur les planches, mais demeurent toutefois pour le moment déconnectés.

Au mois de mai, l'essayiste et romancier Tanaka Komimasa 田中小実昌, alors qu’il travaillait au Tōkyō Forīzu 東京フォリーズ (Tokyo Follies), une salle de Shibuya, dégrafa - tapi derrière le rideau - le soutien-gorge de sa collègue Ranā Ōsaka ラナー多坂 pendant une représentation ${ }^{23}$. Le geste avait peut-être été convenu, mais l'engouement qu'il suscita auprès du public encouragea sa répétition. Aussi anecdotique que puisse paraître le geste de Tanaka, et peu importe au fond qu'il soit le premier ou non à avoir donné l'impression qu'une fille se déshabillait sous les projecteurs, il n'en demeure pas moins une étape importante de l'histoire du striptease au Japon. L'effeuillage, en effet, ne marque à vrai dire que le déplacement d'un état vers un autre. Mais chaque état devient alors virtuellement transitoire, en ce sens qu'un autre, plus désirable encore, pourrait lui succéder. Ce passage de l'état à l'étape marque l'apparition d'une tension dramatique, qui ouvre un univers d'attentes.

Le milieu du théâtre populaire ne tarde pas à apporter sa contribution. En août 1947, Nikutai no mon 肉体の門 (La porte de chair), roman de Tamura Taijirō 田村泰次郎 publié la même année narrant les péripéties d’un groupe de prostituées

22. HARA Yoshiichi 原芳市, Sutorippu no aru machi-ekizotikku shō no sekai wo tanoshimu ストリップのある街ーエキゾティック・ショーの世界を楽しむ (Quartiers de striptease : jouir du monde des shows exotiques), Tōkyō, Jiyū kokuminsha 自由国民社, 1999 , p. 84.

23. TANaKa Komimasa 田中小実昌, 《Sutorippu yōgo shishi 》ストリップ用語私史 (Mon histoire du vocabulaire lié au striptease), Shingeki - tokushū sutorippu 新劇－特集 ストリップ, op. cit., 1973, p. 90-93. 
dans les décombres de l'après-guerre, est porté à la scène par le Kūki-za 空気座 ${ }^{24}$. Durant la pièce, l'une des protagonistes s'attire les foudres de ses camarades en brisant un serment. À l'issue d'un simulacre de procès, ces dernières la ligotent et la déshabillent, avant de lui donner le fouet. La nudité présentée dans La porte de chair n'est certes pas frontale, mais elle n'en demeure pas moins réelle. De plus, elle est comprise dans une séquence et le mouvement y est présent. La thématique développée sur scène anticipe sur la mode à venir des spectacles sadomasochistes. La pièce connut un succès considérable: Watanabe Akio évoque plus d'un millier de représentations ${ }^{25}$. Dans les années 1950, plusieurs théâtres spécialisés dans le striptease la reprirent.

Le striptease arrive donc au Japon avec les Américains, et les conditions de son apparition sur l'archipel sont étrangement proches de celles qui ont vu naitre les premiers spectacles d'effeuillage près d'un siècle plus tôt aux États-Unis, entre les années 1820 et 1860, lors des migrations vers l'Ouest ${ }^{26}$, bien avant qu'il ne se développe en ville sous sa forme théâtralisée ${ }^{27}$. Divers auteurs japonais insistent sur le rôle du striptease, ou plutôt de la salle qui lui est consacrée, comme zone « neutre », de liberté, abolissant les disparités, les différences de niveau social. Il s'agit d'un lieu, d'un moment, permettant d'échapper aux soucis de l'époque ; la dénomination alors couramment employée pour définir ces spectacles, riberaru shōリベラル・ショ - (liberal shows), en est un indice ${ }^{28}$. Aussi, si le caractère érotique de ce genre de

24. Voir Ōzasa Yoshio 大笹吉雄, op. cit., 1998, p. 343.

25. WatAnabE Akio 渡辺昭夫, 《Teito-za gokai gekijō no ichinen kyūkagetsu » 帝 都座五階劇場の一年九力月 (Un an et neuf mois au théâtre du cinquième étage du Teito-za), in Inoue Hisashi 井上ひさし, op. cit., 2001, p. 144.

26. Denys Chevalier, Métaphysique du striptease, Paris, J.-J. Pauvert, 1960, p. 57-60.

27. Dans l'un comme dans l'autre cas, on peut noter un très grand nombre de familles déstructurées, une démographie plaçant les femmes en surnombre, et plus généralement de rudes conditions de vie, caractérisées par l'insécurité et l'instabilité ; John W. Dower, op. cit., 1999, p. 45, 51 et 54 .

28. « Taidan - Nosaka Akiyuki/Wakamatsu Kōji, Sutorippā, yasashisa, Kaihōku » 対談一野坂昭如・若松孝二 ストリッパー・やさしさ解放区 (Entretien : Nosaka Akiyuki/Wakamatsu Kōji, stripteaseuses, gentillesse, zone d'émancipation), Shingeki - tokushü sutorippu 新劇一特集ストリップ,op. cit., 1973, p. 62-71. Le nom de liberal shows dérive de celui d'un kasutori zasshi : Riberaru りべらる (Liberal); HaRA Yoshiichi 原芳市, op. cit., 1999, p. 83. 


\section{CIPANGO}

146 Cahiers d'études japonaises n² 21

spectacle n'est pas à nier - et qu'elles qu'aient pu être les motivations américaines de donner leur blanc-seing pour ce type d'entreprise au Japon - il est probable que le striptease, ainsi que le note Denys Chevalier, corresponde alors tout autant « au désir obscur de la plupart de retrouver des conditions de vie sociale normales $\gg{ }^{29}$, ordinaires pourrait-on dire, qu'au simple fait d'aller s'encanailler. C'est dans ce sens, sans doute, qu'il faut entendre Ozawa Shōichi 小沢昭一 lorsqu’il affirme :

Maintenant que la guerre est finie depuis une vingtaine d'années, à la question de savoir quelle influence a pu avoir sur nous le striptease, et bien je dirais qu'il nous a au moins permis, à nous dont les maisons avaient été détruites par les raids aériens et qui vivions jour et nuit cachés dans des abris, de goûter à un sentiment libérateur; en tout cas à ses débuts.

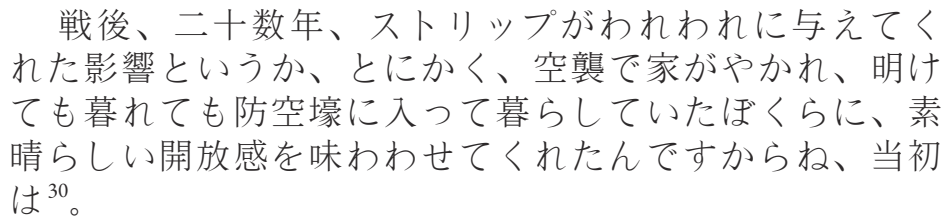

On pourrait enfin ajouter qu'après les années de guerre durant lesquelles l'éducation sexuelle et la production érotique étaient quasiment nulles ${ }^{31}$, l'immédiat après-guerre est une période durant laquelle l'érotisme se développe et se démocratise ${ }^{32}$.

29. Denys Chevalier, op. cit., 1960, p. 57.

30. Ozawa Shōichi 小沢昭一, « Misōde misenai no ga ōgi - Ōnen no mei-sutorippā, Hirose Motomi san »見そうで見せないのが奥義一往年の名ストリッパー・広瀬 モトミさん (Le secret de montrer sans montrer : Hirose Motomi, grande stripteaseuse des premières heures), in Ozawa Shöichi zadan 1 - Jinruigaku nyūmon - Oasobi to gei to 小沢昭 一座談 1 -人類学入門一お遊びと芸と (Causeries avec Ozawa Shōichi, 1 : introduction à l'anthropologie : le divertissement et l'art), Tōkyō, Shōbunsha 晶文社, 2007, p. 52-53.

31. À l'exception de certaines revues ero guro (erotic grotesque) des années 1920-1930 qui circulaient encore sur le marché de l'occasion; Mark McLelland, op. cit., 2010, p. 520.

32. Mark McLelland affirme qu'après-guerre, le gouvernement encourage fortement les trois «s $s-$ sport, screen, sex - au point que les questions d'ordre sexuel sont à cette époque plus aisément traitées dans les médias japonais qu'américains ; ibid., p. 520-523. 


\section{L'âge d'or du striptease (fin des années 1940 et années 1950)}

\section{L'apparition des théâtres-striptease}

C'est à partir de 1948 que l'on peut véritablement parler de striptease, avec la création de théâtres qui lui sont dédiés, les sutorippu gekijō ストリップ劇 場 (théâtre-striptease), tels le Tokiwa-za 常盤座 ou le Rokku-za ロック座, à Asakusa $^{33}$. Les spectacles de nu, jusqu'ici plutôt anecdotiques, prennent une dimension inédite et attirent des spectateurs d'horizons divers, qui feront bientôt passer l'effeuillage du statut de curiosité à celui de phénomène ${ }^{34}$. On notera l'intérêt que lui marquent assez vite des artistes de premier plan, tels le graveur Munakata Shikō 棟方志功 ou l'écrivain Nagai Kafū 永井荷風. Ce dernier note

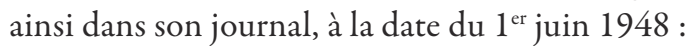

Cet après-midi : loges Daito-za, dans le parc d'Asakusa. Il y eut une rumeur selon laquelle les spectacles de danseuses nues allaient être temporairement interdits, mais ils n'ont ensuite fait que se populariser, et les trois établissements que sont le Tokiwa-za, le Rokku-za et le Daito-za se font actuellement concurrence. Aujourd'hui, j'ai vu au Daito-za une jeune fille en kimono qui, tout en dansant, ôtait sa ceinture rouge et donnait à voir jusqu'à son nagajuban [vêtement porté sous le kimono].

午後浅草公園大都座楽屋。裸体舞踊一時禁止の噂あり

33. Le terme même de strip show (sutorippushōストリップ・ショウ) est utilisé pour la première fois en 1948 par Masakuni Otsuhiko ; HaRA Yoshiichi 原芳市, op. cit., 1999, p. 127.

34. Le striptease remportait alors un tel succès qu'il en était fait usage en diverses occasions, parfois surprenantes. Le Time, dans son article «Japan: Occupational Hazards » du 12 juin 1950, rapporte ainsi qu'en 1950, lors d'élections, une candidate avait réussi à persuader l'une des jeunes filles la soutenant de faire un striptease pour s'attirer plus de votes. Des stripteases avaient aussi vraisemblablement lieu lors de fêtes de temples ou de sanctuaires, dans l'enceinte même du bâtiment religieux, parmi les autres stands forains ; A. W. SAdler, "The Form and Meaning of the Festival", Asian Folklore Studies, vol. 28, $\mathrm{n}^{\circ}$ 1, Nagoya, Nanzan University, 1969, p. 10. 


\section{CIPANGO}

148 Cahiers d'études japonaises n²1

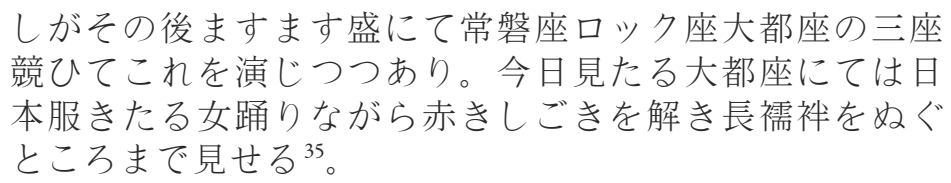

L'ouverture de ces théâtres-striptease représente une étape importante de l'histoire du striptease. En effet, le gakubuchi shō était jusqu'alors pour ainsi dire une excroissance du music hall, l'apanage de structures installées depuis les années 1930 et formant aussi bien danseuses que metteurs en scène. Le passage à des structures plus modestes permet une réorientation du musical vers le burlesque, en d'autres termes une popularisation. Entre 1948 et 1951, des théâtres-striptease ouvrent un peu partout au Japon. Parmi les plus célèbres, aujourd'hui disparus, l'Ōsaka kujō OS gekijō 大阪九条 O S 劇場 à Ōsaka ${ }^{36}$, et l'Asakusa Furansu-za 浅草フラン ス座 à Tōkyō. On compte à cette époque, pour la seule ville de Tōkyō, quatorze établissements consacrés au striptease ${ }^{37}$.

À nouvelles scènes, nouveaux visages. La fin des années 1940 et le début des années 1950 coïncident avec une forte hausse du succès des spectacles de striptease, et l'apparition de nombreuses stars du nu sur scène : Heren (Helen) Taki ヘレ ン滝, Hirose Motomi ヒロセ元美, Jipushī Rōzu ジプシー・ローズ (Gypsy Rose), ou encore Hanī Roi ハニー・ロイ, pour n'en citer que quelques-unes. La renommée de certaines danseuses dépasse désormais le cadre de la salle de spectacle, et certaines feront même une carrière internationale. Ainsi Fujiwara Midori 藤原 みどり qui tournera à Hollywood avec John Wayne ${ }^{38}$, ou Sono Harumi 園はるみ qui ira également aux États-Unis faire carrière dans la chanson avant de poursuivre

35. NAGAI Kafū 永井荷風, Danchōtei nichijō 断腸亭日乗 (Journal de Danchōtei), Tōkyō, Iwanami shoten 岩波書店, 《Iwanami bunko 》岩波文庫, 1987, p. 322.

36. «OS » est la siglaison de Ósaka sutorippu 大阪ストリップ (Ósaka strip).

37. Ozawa Shōichi 小沢昭一, Fuka Toshihiko 深井俊彦, NAKATANi Akira 中谷陽, op. cit., 1973, p. 99.

38. Dans le film The Barbarian and the Geisha (1958) de John Huston, Fujiwara reprend pour l'occasion son vrai nom, Andō Eiko 安藤永子. 
au Japon ${ }^{39}$. Par ailleurs, le striptease gagne la reconnaissance du monde artistique. Nagai Kafū 永井荷風 épouse Merī Matsubara メリ一松原, et Munakata Shikō se plaît à dire de Gypsy Rose qu'elle « a le corps d'une déesse » ${ }^{40}$. Gardons-nous toutefois de surestimer les apports d'une telle reconnaissance pour la carrière d'une stripteaseuse. Si le monde du striptease ne tourne pas en vase clos, c'est toutefois bel et bien à l'intérieur de celui-ci, en se produisant sur scène, que les danseuses se forgent une réputation. Leur nom est alors fréquemment associé à une technique qui leur serait propre ou un type de numéro qu'elles seules proposeraient. En quelque sorte, l'effeuilleuse fait corps avec son art, on l'identifie à ce dernier. Ainsi, le nom de Hirose Motomi est régulièrement accompagné d'une mention de sa fameuse fan dance ファンダンス (danse à l'éventail), dont Tanaka livre la description suivante :

Pendant la première période du striptease, la fan dance de Hirose Motomi, qu'on disait fraîchement rentrée de Shanghai, était vraiment sexy. Elle agitait devant elle de grands éventails ornés de plumes qu'elle déplaçait de haut en bas. Un éventail glissait sur son corps, sa peau se dévoilait, de plus en plus, sous son nombril, et à l'instant où on allait pouvoir guigner entre ses cuisses, un autre éventail venait la recouvrir gentiment. Les stripteaseuses de l'époque n'étaient pas cul-nul, elles portaient des butterfly [slips triangulaires] ou des culottes, mais avec ses grands éventails, elle se cachait tout en s'exhibant furtivement, si bien qu'on aurait vraiment dit qu'elle ne portait rien en dessous.

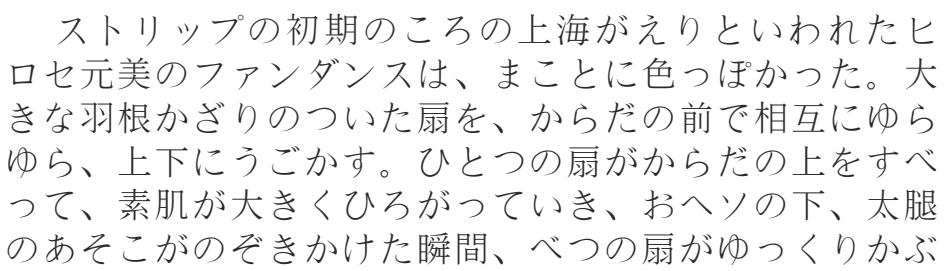

39. Hasнiмото Yoshio 橋本与志夫, « Natsukashi no sutā tachi » 懐かしのス夕一 たち (Les stars d'antan), Shingeki - tokushū sutorippu 新劇一特集ストリップ,op. cit., 1973, p. 28-35.

40. Kami no yō na nikutai da 神のような肉体だ; $S N N Z$, vol. 8, p. 38. 


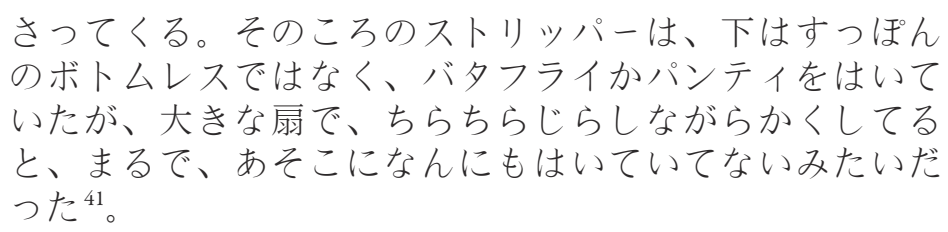

Une icône de l'effeuillage : Gypsy Rose

Arrêtons-nous quelques instants sur la trajectoire de Gypsy Rose, probablement la plus emblématique des danseuses nues japonaises. De son vrai nom Shimizu Toshiko 志水敏子, elle naît dans le département de Fukuoka en $1934^{42}$. Elle arrive à Tōkyō avec une troupe de théâtre itinérant qui se produit devant un public de militaires américains. Masakuni Otsuhiko travaille alors au Tokiwa-za et cherche une danseuse pour remplacer Helen Taki, l'étoile du théâtre, dont le goût pour la boisson menace les spectacles. Lorsque Masakuni repère Shimizu, cette dernière est tout juste âgée de seize ans. Elle monte pour la première fois en juin 1950 sur les planches du Tokiwa-za, où elle danse en uniforme scolaire. Masakuni, devenu son agent, lui suggère alors pour nom de scène Gypsy Rose, vraisemblablement en hommage à la célèbre effeuilleuse américaine Gypsy Rose Lee. Elle devient peu après la première ambassadrice du grind (déhanchement circulaire suggestif que l'on pourrait traduire par « frotti-frotta ») au Japon. Elle se fera surtout connaître à partir de 1952, où son grind dans Arabian Naito アラビアン・ナイト (Les mille et une nuits) est interdit par la police parce qu'il « suscite une excitation trop intense ${ }^{43}$ !

Le charme exotique de Gypsy Rose et la réputation sulfureuse de son déhanchement lui procurent une renommée sans précédent, au point qu'elle signe un contrat de deux ans avec le Nichigeki myūjikku hōru 日劇ミュージックホ

41. TANAKA Komimasa 田中小実昌, Vinasu no ekubo - Tanaka Komimasa sakubinshū ヴィーナスのえくぼー田中小実昌作品集 (Les fossettes de Vénus : recueil des œuvres de Tanaka Komimasa), vol. 1, Tōkyō, Shakai shisōsha 社会思想社, 1990, p. 280.

42. Fukuoka est, avec Ōsaka et Tōkyō, l’une des trois grandes villes « historiques » du striptease au Japon ; Ozawa Shōichi 小沢昭一, Fuka Toshihiko 深井俊彦, NAKATANi Akira 中谷陽, op. cit., 1973, p. 104.

43. Amari ni mo shigekiteki dearu あまりにも刺激的である; SNNZ, vol. 8, p. 39. 
ール (Nichigeki Music Hall). Au terme de celui-ci, elle sombre dans l'alcool et reprend ses activités à son compte. Elle tourne définitivement le dos au spectacle en 1965 et ouvre, avec Masakuni, un snack-bar dans le département de Yamaguchi. Elle meurt deux ans plus tard, à l'âge de trente-deux ans. Peu de stripteaseuses goûtèrent à une gloire équivalente, mais nombreuses furent celles qui connurent une fin analogue et tragique ${ }^{44}$; les conditions de travail sont en effet des plus difficiles dans la profession. Tanaka Komimasa 田中小実昌 raconte par exemple que les danseuses mangeaient souvent peu et mal, travaillaient beaucoup (de l'ordre de trois à quatre représentations par jour), et ce quasiment toute l'année. Elles ne sortaient pour ainsi dire jamais de leur lieu de travail qui était aussi leur lieu de vie, et étaient véritablement coupées du monde ${ }^{45}$. Leur espérance de vie se trouvait fortement réduite par de telles conditions.

\section{Fonctionnement des théâtres}

Penchons-nous sur le fonctionnement de ces théâtres-striptease. Asakusa offre à cet égard une vitrine intéressante. Quartier historique de divertissements, avec parc d'attraction, temples, cinémas, théâtres, restaurants et bars, Asakusa ne compte à l'époque pas moins de cinq salles de striptease, qui se livrent une féroce

44. Aramata Hiroshi 荒俣宏 relève ainsi plusieurs cas de suicide et de décès précoces par overdose, excès d'alcool ou maladies, survenus avant les années 1960, dans Banpaku to sutorippu 万博とストリップ (Expositions universelles et Striptease), Tōkyō, Shūeisha shinsho 集英社新書, 2000, p. 218-220.

45. Il donne notamment l'exemple d'une jeune fille qui, en trois ans, n'a pas quitté son lieu de travail un seul jour, et évoque également l'absence totale de journaux, quels qu'ils soient. Les danseuses pouvaient donc vivre dans la plus complète ignorance du monde extérieur ; TANAKA Komimasa 田中小実昌, «Gohan no obake»ゴハンのオバケ (L'esprit du repas), Shingeki - tokushū sutorippu 新劇一特集ストリップ,op. cit., 1981, p. 24-27. Ōкиво Katsuhiko 大久保克彦 ajoute que les rares congés que les danseuses pouvaient prendre n'étaient pas payés, ce qui n'encourageait guère au repos, dans 《Tokudashi to shimin seikatsu »特出しと市民生活 (Le Tokudashi et la vie civile), ibid., p. 49. 


\section{CIPANGO}

152 Cahiers d'études japonaises n²1

concurrence $^{46}$. La proximité du Yoshiwara 吉原, le quartier des plaisirs, lui assure, jusqu'au démantèlement de ce dernier en 1958, une fréquentation relativement stable. Les spectacles de striptease y durent alors environ deux heures : une heure de sketches pour une heure de striptease. Les numéros pouvaient évidemment s'agencer en alternance, mais en règle générale, le comique précédait l'effeuillage, sur le modèle du burlesque américain. Les théâtres donnaient en moyenne trois représentations par jour, chaque jour de l'année. À en croire Inoue Hisashi 井 上ひさし, le Furansu-za employait en 1956 une cinquantaine de personnes ${ }^{47}$ : vingt-quatre danseuses, deux danseurs, six musiciens, une dizaine de comiques et une petite dizaine de personnes en coulisses. Sans assurance maladie, avec un salaire de base particulièrement modeste, les conditions de travail étaient rudes pour les employés. D’autant que les qualifications requises étaient élevées. La majeure partie des danseuses avait en effet été formée au Shōchiku Kageki Dan 松竹歌劇団 (SKD), l'un des principaux théâtres de revues au Japon ${ }^{48}$. Les filles elles-mêmes étaient, au sein du Furansu-za, réparties en trois catégories : celles qui ne montraient rien - les danseuses standards (futsū no odoriko 普通の踊り子) celles qui montraient leur poitrine - les semi-nues (semi-nūdo セミ・ヌード) et enfin les nues (nüdo ヌード), celles dont « le salaire est d'autant plus élevé que la culotte est éloignée du nombril ${ }^{49}$ ainsi que se plaît à les qualifier Inoue.

46. Il est à noter que ces établissements étaient pour la plupart de dimensions très modestes. Le dessinateur et essayiste japonais SENŌ Kappa 妹尾河童 en propose un intéressant aperçu dans 《Kappa ga nozoita sutorippu gekijō » 河童が司見いたストリ ップ劇場 (Les théâtres-striptease surpris par l'œil de Kappa), Geinō tōzai - Sutorippu dai tokushū 藝能東西ーストリップ大特集 (Geinō tōzai : grand numéro spécial sur le striptease), Tōkyō, Atarashii Geinō kenkyū-shitsu 新しい芸能研究室, 1977, p. 58-63.

47. Inoue Hisashi 井上ひさし, «Asakusa Furansu-za wa kigeki no gakkō datta » 浅 草フランス座は喜劇の学校だった (L’Asakusa Furansu-za était une école pour la comédie), Asakusa Furansu-za no jikan 浅草フランス座の時間, op. cit., 2001, p. 12.

48. De manière générale, la plupart des danseuses avaient reçu une solide formation de danse avant d'en arriver au striptease. Nombre d'entre elles venaient du ballet, d'autres de la danse acrobatique. Pour certaines, se tourner vers le striptease n'était pas vraiment un choix, mais plutôt une porte de sortie lorsque l'accès à des théâtres plus prestigieux ne leur était pas - ou plus - offert ; Hasнiмото Yoshio 橋本与志夫, op. cit., 1973, p. 28-35.

49. InOue Hisashi 井上ひさし, op. cit., 2001, p. 13. 
L'uniforme de la danseuse nue pendant les années 1950 se résume à un butterfly (batafurai バタフライ) et des paillettes sur les seins visant à en cacher la pointe (supankōru スパンコール, spangle), de même que dans le burlesque américain.

Le passage du striptease de structures telles que les grands établissements de music hall, à celles plus modestes de théâtres de boulevard provoqua des changements dans les conditions de travail, notamment en ce qui concerne l'organisation du recrutement. En effet, là où les danseuses étaient souvent directement liées à la compagnie, les stripteaseuses de boulevard passaient plutôt par l'intermédiaire d'agents, ou himo 紐. Cela permettait aux théâtres de renouveler plus souvent leurs têtes d'affiche, et aux effeuilleuses de se produire devant différents publics, accédant ainsi peut-être à une renommée plus large. L'existence d'un intermédiaire représentait évidemment une charge financière supplémentaire pour la danseuse, mais lui assurait aussi une certaine sécurité. Remarquons au passage que l'agent d'une danseuse était dans bien des cas, dont celui de Gypsy Rose, son amant ${ }^{50}$.

Nous assistons durant les années 1950 à des glissements terminologiques. Les termes nüdo ヌード (nude) et sutorippā ストリッパー (stripper) finissent par

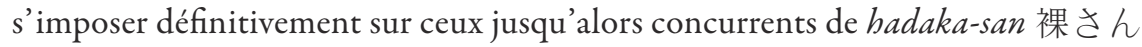
(la nue) et odoriko 踊り子 (la danseuse). Les titres des spectacles participent de ce même mouvement. La lecture du programme de l'année 1952 du Nichigeki fait ainsi découvrir des shows dont les titres - pour la plupart issus de l'anglais semblent tout droit sortis de films américains : Tökyō no Ivu 東京のイヴ (L’Ève de Tōkyō), Rabu hābā ラブ・ハーバー (Love Harbor), Janguru ravu ジャング ルラヴ (Jungle Love), Randebūランデブー (Rendez-vous), ou encore Sanmā sukyandaru サンマースキャンダル (Summer Scandal), pour n'en citer que quelques-uns ${ }^{51}$. Ce penchant pour l'exotisme et les vocables étrangers se retrouve aussi dans les noms des danseuses : Helen Taki, Grace Matsubara, Marie Shinjū, ou encore Pearl Hamada. Tout semble indiquer qu'il s'agit là d'une mode propre à

50. Le terme himo est évocateur : il peut également désigner, dans le cas de la prostitution, le maquereau.

51. Voir The Tsubouchi Memorial Theater Museum Digital Archives Collection. Nous remercions Jonathan Bollen, enseignant en art dramatique à l'Université Flinders (Australie), pour ses indications. 


\section{CIPANGO}

154 Cahiers d'études japonaises n²1

cette époque de libération, mais également d'occupation américaine qui culmine avec l'apparition combinée en 1953 des gaijin nūdo shō 外人ヌードショー (nude shows d'étrangères), présentant d'authentiques occidentales, et des kinpatsu sutorippu 金髪ストリップ (stripteases de blondes) tenus par des autochtones affublées de perruques blondes ${ }^{52}$.

\section{Innovations scéniques}

Parmi les innovations scéniques, les spectacles de baignade (nyūyoku shō 入浴シ $\exists-$ ) qui avaient, au début du siècle, remporté un vif succès en Occident font leur apparition ${ }^{53}$ : une baignoire (ou un simple baquet) est apportée sur scène, on l'emplit d'eau chaude, puis une jeune fille se déshabille pour prendre son bain. Le caractère quotidien, familier quoique érotique, participe du succès de ces représentations, en ce qu'il exacerbe le sentiment d'intimité qui lie la stripteaseuse au public. Le nyūyoku shō est un premier pas vers des spectacles où le client n'est plus uniquement spectateur, passif, mais devient dans une certaine mesure acteur de son propre plaisir. Le dispositif permet aussi, outre divers jeux avec la mousse, une certaine forme d'interaction, les spectateurs ayant la possibilité - moyennant supplément - de savonner le dos de la baigneuse, ou encore de faire monter la température de l'eau en soufflant sur les braises du foyer et donc d'observer l'actrice d'un peu plus près ${ }^{54}$. En juillet 1951, l'Asakusa-za 浅草座 et le Bijin-za 美人座, situés tout deux à Asakusa, s'affrontent avec une baignoire japonaise d'un côté, occidentale de l'autre.

52. On se souviendra qu'en Occident également, dans la littérature comme dans le striptease notamment, l'érotisme a souvent été de pair avec l'exotisme, d'où le succès du personnage de l'odalisque par exemple. Au Japon, cet « exotisme » passe alors par ce que nous pourrions qualifier d' « occidentalisme ».

53. Les différentes sources ne s'accordent pas sur les dates, mais il semblerait que ces spectacles apparaissent au Japon entre la fin des années 1940 et le début des années 1950.

54. HirookA Keiichi 広岡敬一, Sutorippu bojō-Asakusa, Yoshiwara romanesuku ストリップ慕情一浅草・吉原ロマネスク (La nostalgie du striptease : Asakusa, Yoshiwara romanesque), Tōkyō, Kōdansha 講談社, « Kōdansha bunko » 講談社文庫, 1993, p. 24-25. 
Autre nouveauté : le rittai sutorippu 立体ストリップ (《striptease surélevé »), un show utilisant une échelle arquée passant au-dessus des spectateurs. Ceux-ci doivent donc lever les yeux pour observer les danseuses qui y grimpent et prennent des poses laissant entrevoir des parties choisies de leur anatomie ${ }^{55}$.

Créés au milieu des années 1950, c'est essentiellement vers la fin de ces mêmes années que s’imposent les bed shows (beddo shōベッド・ショー). Que le dispositif soit des plus rudimentaires explique, du moins en partie, la généralisation de ce genre de numéro. Il suffit en effet d'un lit sur une scène et d'une stripteaseuse. Cette dernière est amenée à se mettre au lit, puis - et il s'agit là d'une véritable nouveauté - à y prendre du plaisir de manière ostentatoire. Aussi simple que soit le canevas, il permet une infinité de variations. La fille peut feindre de se caresser sous les draps, mimer l'amour avec un oreiller, utiliser des ustensiles, faire appel à un ou une partenaire, etc. Le succès remporté par les bed shows s'explique probablement par le caractère sulfureux, le franchissement d'un nouveau cap dans l'interdit. Mais le fait que les danseuses y deviennent plus facilement interchangeables a également son importance : en effet, la chorégraphie à retenir pour un bed show est nettement moins complexe que celle d'un numéro de danse solo et permet de multiplier les représentations. L'avènement du bed show constitue un véritable déplacement du registre « non figuratif » ou suggestif de la danse à un autre, ouvertement mimétique; la danseuse se fait actrice. À partir des années 1960, les spectacles vont évoluer pour laisser de plus en plus de place à la simulation de l'acte sexuel. Cela constitue un virage par rapport à l'effeuillage gentiment aguicheur qui était jusqu'alors de mise, et l'un des points de départ de ce que les nostalgiques des premières heures considèrent comme le déclin du striptease. D'autres saynètes, aux connotations sexuelles plus marquées encore, vont dès lors apparaître.

\section{Du spectacle plaisant au plaisir spectaculaire : effeuillage et sex show (années 1960 et 1970)}

\section{Du burlesque au sex show}

La disparition progressive des comiques dans les théâtres-striptease d'Asakusa vers

55. Ibid. 
156 Cahiers d'études japonaises n²1

la fin des années 1950 s'explique volontiers par la « concurrence déloyale » que leur livrent les danseuses. Et le déséquilibre qui en résulte dans la structure des spectacles peut ainsi s' interpréter comme une tendance du striptease vers toujours plus de licence. Il existe néanmoins un autre facteur, également lié à un problème de concurrence : la télévision, qui en 1958 a déjà intégré le quotidien des foyers standards au Japon. On peut évoquer ici le cas du comique Atsumi Kiyoshi 渥美 清 qui, à partir de 1955, bâtit sa renommée au Furansu-za, puis se dirige, en 1961, vers les plateaux de la NHK, avant de s'essayer au cinéma et de devenir, en 1969, Tora-san 寅さん, héros bien connu de la série de films Otoko wa tsurai yo 男は つらいよ (C'est dur d'être un homme). En pleine expansion, le marché de la télévision absorbe en réalité grand nombre de comiques issus du monde du striptease, leur offrant une situation plus confortable. Les salaires y sont plus conséquents et la renommée potentielle sans commune mesure. Au regard des conditions de travail précaires dans les théâtres-striptease, dont témoigne l'ouvrage de Kitano Takeshi 北野武 Asakusa Kid ${ }^{56}$, la télévision représentait bel et bien pour les comiques un débouché vers le haut.

Les changements survenus dans le paysage du théâtre-striptease sont concomitants au lent déclin de la popularité d'Asakusa. Cette époque coïncide aussi avec la fermeture du Yoshiwara, le 31 mars 1958, dont on ne peut nier qu'elle eut, parmi d'autres facteurs liés à l'urbanisation, des conséquences sur le taux de fréquentation d'Asakusa, mais qui ne semble pas avoir eu un impact notable sur l'évolution des spectacles de striptease. Le commerce de la chair ne constituait certes pas la seule activité lucrative pratiquée au Yoshiwara, pourtant il nous paraît peu discutable que sa fermeture soit à inscrire dans un mouvement anti-prostitu-

56. Kitano Takeshi 北野武, Asakusa Kid, Paris, Le Serpent à Plumes, « Motifs », 2001. 
tion plus vaste ${ }^{57}$. Or celui-ci épargna les théâtres-striptease. Il est significatif de constater ici qu'en dépit d'une réputation déjà sulfureuse et d'une situation limitrophe, le striptease n'était alors pas associé à la prostitution. Les descriptions des conditions de vie concrètes des stripteaseuses sont, il est vrai, assez rares, ce qui ouvre la porte à toutes les hypothèses. Nous avons évoqué la place du souteneur, ainsi que le cloisonnement des filles. Le sort des danseuses était-il plus enviable que celui des prostituées ? Il subsiste, quoi qu'il en ait été, une différence fondamentale, engendrée par le caractère spectaculaire du striptease. Outre la dimension voyeuriste, c'est la satisfaction même du désir qui diffère. Contrairement à la prostitution, qui relève pour ainsi dire de la performance, dans la mesure où l'acte sexuel y est consommé, le spectacle d'effeuillage n'est qu'une mise en scène. Chevalier précise à ce propos :

Considérée uniquement sous l'angle de l'érotologie, la qualité érotique du numéro de la stripteaseuse est absolument indépendante de ses deux phases : déshabillage et pantomime amoureuse. Aussi bien, la nudité est moins une manifestation érotique en soi qu'une ouverture vers une éventualité érotique. [...] Au demeurant, la négation de l'offre, négation de ses conséquences plutôt, augmente la valeur de la proposition initiale. En ce sens, la stripteaseuse incarne parfaitement la notion traditionnelle d'érotisme, et non pas la prostitution dans laquelle l'offre n'est suivie d'aucune rétractation ${ }^{58}$.

Si le striptease est l'expression du désir masculin de dominer la femme, il dit aussi qu'il ne s'agit pour l'homme que d'un vœu pieux. La romancière Michèle Perrein va jusqu'à y voir le triomphe de la femme :

57. En termes de lutte contre la prostitution, cette fermeture s'avère du reste toute relative : il ne fallut que quelques mois pour qu'ouvre, en juillet, le premier torukoトル $\sqsupset$ du quartier. Apparus au milieu des années 1950, les «bains turcs » (toruko buro 卜 ルコ風呂) fonctionnaient de fait comme des maisons closes. Ils prirent par la suite le nom de sōpu rando ソープランド (soapland) ; Koyano Atsushi 小谷野敦, Nihon no baishunshi - yūkō jofu kara sōpu rando made日本の売春史一遊行女婦からソープラ ンドまで (Histoire de la prostitution au Japon : des amuseuses itinérantes au soap land), Tōkyō, Shinchōsha 新潮社, 2007, p. 181-187.

58. Denys Chevalier, op. cit., 1960, p. 107-108. 
Je ne considère pas le striptease avilissant pour la femme puisqu' il monte en épingle le seul moment triomphant de la femme, celui où elle exerce à l'état pur son pouvoir sur l'homme, sans aller jusqu'au moment où l'homme sera le maître ${ }^{59}$.

Le brouillage des délimitations ira pourtant croissant. En fait, nous assistons depuis la fin des années 1950 à une généralisation, une banalisation diront certains, des questions d'ordre sexuel. Films et magazines présentent des images de plus en plus osées. La tendance se confirme encore dans le milieu des années 1960, avec l'avènement des pinku eiga ピンク映画 (films roses) ${ }^{60}$. Or, si le phénomène est indissociable de la marchandisation du sexe via les médias de masse, il est également étroitement lié à la montée d'une logique contestataire. L'un des pionniers du genre, Takechi Tetsuji 武智鉄二, metteur en scène de théâtre à l'origine, collabore avec le monde du striptease au point qu'il en vient à monter un nô nu sur les planches du Nichigeki en 1956. Takechi croit alors fermement au pouvoir subversif de l'obscène, ainsi qu'à sa capacité à renverser l'ordre bourgeois. C'est dans le même état d'esprit qu'il prend la caméra pour tourner Hakujitsumu 白日夢 (Rêves en plein jour), distribué par la Shōchiku en $1964^{61}$. Des cinéastes tels qu'Imamura Shōhei 今村昌平, Ōshima Nagisa 大島渚 ou Wakamatsu Kōji 若 松孝二 abordent fréquemment les thèmes du désir, de l'érotisme et du sexe dans leurs œuvres. Les grands studios quant à eux, Tōei et Nikkatsu pour l'essentiel, attendront le début des années 1970 pour se lancer dans l'aventure.

Tout comme au cinéma, défier la censure devient un enjeu pour le striptease. L'idéologie y est toutefois moins présente. En effet, si le désir naît de l'interdit

59. Michèle Perrein, «Une enquête sur le striptease », in André Breton (dir.), Le Surréalisme, même, vol. 4, Paris, J.-J. Pauvert, 1958, p. 63.

60. Jasper SHARP, Behind the Pink Curtain: the Complete History of Japanese Sex Cinema, Godalming, FAB Press, 2008, p. 51-122.

61. TAKECHI Tetsuji 武智鉄二, 《Sutorippu no kachi tenkan »ストリップの価值転 換 (Changement des valeurs dans le striptease), Shingeki - tokushū sutorippu 新劇一特 集ストリップ,op. cit., 1973, p. 72-77. 
- ou plutôt du non-sens de l'interdit ${ }^{62}$ - la définition de ce dernier est sans cesse remise en cause, provoquant - pour ce type d'établissements notamment - une sorte de « course à la transgression ». Le début des années 1960 voit fleurir le Kansai sutorippu関西ストリップ (striptease du Kansai), dont l'appellation suggère que les spectacles de striptease ont, dans cette région, pris un tour particulier. L'affaire reste peu documentée et le seul témoignage que nous sommes parvenus à recenser fut publié en 1964 dans la revue française Arts. Dans un article proposant au lecteur en quête d'exotisme un florilège de clichés injurieux et racistes - saupoudré d'un soupçon de misogynie - Jean-Clarence Lambert décrivait par ces mots les toruko et striptease dont il avait pu faire l'expérience dans le Kansai :

[C'est] un «turku », c'est-à-dire un bain turc. [...] Voici qu'apparaît mon opératrice. [...] Elle n'a aucun charme physique, comme la grosse majorité de ses compatriotes. Pas de chevilles, des jambes courtes, à peine une taille; et les seins ? où mettent-elles leurs seins ? Et ce visage de «pâtes-la-Lune », presque sans yeux, sans sourcils, sans nez... [...]

Il faut parler aussi des «skins-shows » et des «nude-shows », tels qu'on en voit à Kyoto (Kyoto, la ville la plus traditionnellement raffinée du Yamato !) [...]. Il s’agit de strip-teases bon marché qui se terminent par l'exposition absolue de la jeune personne (le plus souvent laide et sans charme). La position finale est au centre de la scène, le corps versé en arrière, les jambes bien écartées, « pire que nue $\gg$. Au premier rang, on croirait une leçon d'anatomie interne ${ }^{63}$.

L'expression même de Kansai sutorippu semble n'avoir eu en fait cours qu'en région métropolitaine. Le terme sera du reste très rapidement concurrencé par celui de zen-suto 全ス卜 (《striptease intégral »), dans lequel la nudité est aussi totale que nous la concevons actuellement. Le tokudash $i$ 特出 $L$, contraction de tokubetsu shutsuen 特別出演 (《 performance spéciale 》), va lui succéder. À l'ori-

62. Jean Baudrillard, De la séduction, Paris, Gallimard, « Folio », 1992, p. 105.

63. Jean-Clarence LAmberT, «Images choisies d'un Japon sordide et magnifique », ARTS : lettres, spectacles, musique, $\mathrm{n}^{\circ}$ 972, Paris, 1964, p. 39. 
160 Cahiers d'études japonaises n² 21

gine organisé autour du numéro d'une stripteaseuse invitée, dont la présence à l'affiche est «spéciale », celui-ci va bientôt prendre un autre tour : l'exhibition systématique des parties génitales lève le doute quant au sens qu'il faut attribuer à cette « performance spéciale ${ }^{64}$.

Bien rares furent les théâtres à proposer ouvertement des numéros de ce type, et nous touchons ici à une dimension épineuse du striptease, celle de ses rapports avec le Code pénal japonais, et plus particulièrement les articles 174 et 175. Le premier concerne l'effeuilleuse : il sanctionne l'obscénité publique; le second interdit sa commercialisation et cible l'exploitant. Pour agir, la justice doit donc prouver qu'il y a bien eu obscénité. Or, spectateurs, exploitants et stripteaseuses ne se montrent pas toujours très coopérants, et bien souvent l'obtention de la preuve recherchée est le fait d'une infiltration policière. À quelques exceptions près, les seules traces de tokudashi dont nous disposons officiellement se limitent ainsi aux inculpations, procès et condamnations. Le cas Ichijō Sayuri一条さゆり (1929/1937-199765) est à ce propos relativement bien documenté ${ }^{66}$. Cette dernière a fait l'objet, entre 1963 et 1971, de neuf plaintes pour obscénité publique. Elle est finalement interpellée par la police d'Ōsaka en 1972, pendant sa tournée d'adieu. Condamnée à quatre mois de prison, elle fait appel. Le tribunal d'Ōsaka confirme la sentence. Ichijō en réfère alors à la Cour suprême. Le verdict tombe en janvier 1975 : six mois de prison ferme. Ses déboires avec la justice lui attirent

64. Shiota Masaru 塩田勝 (dir.), Ryūkōgo ingo jiten 流行語・隠語辞典 (Dictionnaire de parler populaire et d'argot), Tōkyō, San.ichi shobō 三一書房, 1981, p. 215.

65. La naissance d'Ichijō Sayuri est entourée de mystère. Elle serait née, selon les sources, en 1929 ou 1937, et dans les préfectures de Niigata ou Saitama ; IsHikAWA Hiroyoshi 石 川弘義 (dir.), Taishū bunka jiten 大衆文化辞典 (Encyclopédie de la culture populaire), Tōkyō, Kōbundō 弘文堂, 1991, p. 51.

66. Sugrura Seiken 杉浦正健, « Ichijō Sayuri igo no Ichijō Sayuri - Saiban kiroku wo moto ni kangaeru »一条さゆり以後の一条さゆり一裁判記録をもとに考える (Ichijō Sayuri après Ichijō Sayuri : réflexions sur la base des enregistrements des procès), Geinō tōzai - Sutorippu dai tokushū 藝能東西ーストリップ大特集, op. cit., 1977, p. 208-233. 
soutien et sympathie de divers groupes politiques, féministes notamment ${ }^{67}$. En effet, la ligne de défense qu'elle adopte la distingue de ses collègues stripteaseuses. Alors que d'ordinaire celles-ci plaident l'accident ou l'étourderie, Ichijō en appelle elle à la liberté d'expression, et son procès s'inscrit dans l'illustre lignée de ceux qui opposèrent le monde de l'art à la censure. Lorsqu'une peine de prison sanctionne une performance, la liberté d'expression se trouve certes nécessairement en jeu quelque part. L'argument est toutefois nouveau. Dans le monde du striptease, cette attitude de transgression frontale tranche avec celle qui jusqu'alors avait consisté à rechercher des points de fuite, dont la balançoire de Masahiko était emblématique.

\section{Où l'on passe d'une séduction jouée à un jeu séducteur}

Le glissement de la danseuse vers l'actrice, qui marque la fin de l'âge d'or du striptease, se traduit par une manière tout autre d'envisager la création des shows : de la séduction mise en spectacle des débuts, on passe à des spectacles essayant de séduire, à une machination séductrice se voulant spectacle. L'attraction, la séduction, pour reprendre les termes de Baudrillard, ne naissent « surtout pas [d'] un désir signifié, mais [de] la beauté d'un artifice $\gg^{68}$. Naïveté et désinvolture apparentes constituaient des éléments précieux, qui participaient de la séduction, du pouvoir de fascination, et nous pourrions dire, en généralisant quelque peu, que l'équilibre de ces spectacles reposait en grande partie sur cet effet d'ingénuité feinte. Le succès des nyūyoku shō procède d'une naïve banalité. Durant les années 1950, les accessoires étaient principalement utilisés pour dissimuler de manière amusante ce que l'on souhaitait laisser imaginer : mousse du bain, éventails, ballons, etc. Ceci n'est pas sans évoquer la légende selon laquelle le premier striptease parisien aurait été causé par une puce : la danseuse, sur scène, aurait alors mis tant de zèle à sa

67. Ogura Takayasu 小倉孝保, Shodai Ichijō Sayuri densetsu - Kamagasaki ni chitta bara 初代一条さゆり伝説一釜ヶ崎に散つたバラ(Légende d'Ichijō Sayuri première du nom : la rose qui dépérit à Kamagasaki), Ōsaka, Yōbunkan shuppan 葉文館出版, 1999, p. 133.

68. Jean BAUDRILlARD, op. cit., 1992, p. 107. 


\section{CIPANGO}

162 Cahiers d'études japonaises n²1

capture, fouillant dans son costume, qu'elle se serait dévêtue bien malgré elle. En d'autres termes, les ficelles, trop grosses, laissent moins de place à l'imagination ; moins suggérée que présentée sur un plateau, l'offre de séduction change à partir des années 1960 le caractère des spectacles de nu. Hirooka décrit ainsi une performance d'Ichijō Sayuri en 1971, à Funabashi :

Elle se déshabilla en musique, puis se brûla le corps avec les flammes d'un fagot de bougies. La cire fondue perlait sur sa peau, on aurait juré qu'elle la lui cramait. Alors que, suffocante, elle endurait la chaleur, son expression passa bientôt du supplice à la jouissance. Elle enfouit sa main entre ses cuisses et astiqua la jointure de ses plis découverts, il en ruissela des gouttelettes transparentes, son corps entier devint la proie de violentes secousses et des cris perçants jaillirent de sa gorge.

曲に合わせながら衣装を脱ぐと、束ねた百目蛹燭の炎 で裸をあぶる。溶けた蛹が雫になって肌に滴り落ち、そ のあたりの肌を焦がすかのよう。息を詰めながら熱さに 耐える彼女の表情は、やがて地獄の責め苦から喜悦に変 わつた。片手の指が股のあいだを探り、剥き出しの譬の 合わせ目に蚌かすと、その場所から透明な雫が溢れ、全 身を細かく激しい振動が襲つて、鋭い悲鳴が彼女の喉か らほとばしる。

De manière générale, les théâtres-striptease s'écartent, dans les années 1960, du burlesque. Ils dépouillent leurs spectacles des numéros de comiques tout en intensifiant le caractère sexuel des performances de nus. Nous assistons à l'apparition de diverses déclinaisons du sexe sur scène : aux bed shows succèdent les Tengu beddo 天狗ベッド, au cours desquels le nez d'un masque de Tengu ${ }^{69}$ sert de jouet sexuel. Les numéros solos adoptent ainsi pour la plupart un tour plus masturbatoire, et le vagin occupe dès lors une place prépondérante. Certaines performances

69. Créature légendaire dont le nez, très allongé et dressé vers le haut, évoquait, bien avant le striptease, l'organe masculin. 
ne tardent pas à offrir au spectateur une véritable auscultation du sexe féminin ${ }^{70}$. Nommés furu ōpun フル・オープン (full open, en référence à l'ouverture des jambes), ces shows présentent une approche inédite puisqu'il ne s'agit plus tant de voyeurisme (au sens de voir à la dérobée, voler une image interdite) que d'une plongée dans le corps de l'autre, jusqu'au recours à des instruments de gynécologie, lors de spectacles où l'œil scrute, au-delà du réel, un sexe hyperréaliste ${ }^{71}$. Qu'on ne s'y trompe toutefois pas : l'utilisation d'appareils permettant une observation plus fouillée ne constitue pas une innovation en soi $^{72}$. La nouveauté des furu ōpun réside dans leur nature pleinement et ouvertement exhibitionniste. La stripteaseuse montre plus qu'elle ne cache.

L'importance que revêt l'exhibition du sexe sur scène, sous sa forme anatomique ou masturbatoire, est parallèle à la réorientation du striptease vers le sex show, qui entraîne dans sa course l'apparition de spectacles mettant en scène plusieurs partenaires. Les chronologies se montrent très discrètes à ce propos. Néanmoins il semble que les shows sadomasochistes (zankoku shō 残酷ショー, « shows cruels »), en vogue pendant les années 1960, aient joué le rôle de pionnier. Quant au spectacle de la relation sexuelle à proprement parler, les « shows lesbiens » (resubian shōレスビアン・ショー) précèdent l'arrivée de leur version hétérosexuelle, appelée shirokuro shō 白黒ショー (《show noir et blanc»). En 1972, la dimension participative de la performance de l'acte sexuel franchit

70. L’illustrateur OnOzawa San.ichi おのざわさんいち en propose un panorama intéressant dans «E de miru sutorippu-shi » 絵で見るストリップ史 (L'histoire du striptease par le dessin), Geinō tōzai-Sutorippu dai tokushū 藝能東西ーストリップ大 特集, op. cit., 1977, p. 4-15.

71. Ces shows ne sont pas sans évoquer la nouvelle d'Alphonse Allais dans laquelle un rajah, s'ennuyant, demande à une jeune fille qu'elle danse et se dénude, pour lui. Une fois celle-ci complètement nue, il s'exclame : « Encore !», et ses serviteurs lui ôtent la peau ; Alphonse Allais, «Un rajah qui s'embête : conte d'Extrême-Orient », Rose et VertPomme (cuvres anthumes), Paris, Paul Ollendorff, 1894, p. 269-274.

72. Cette pratique avait déjà eu cours lors de certains nyūyoku shō. Les spectateurs ayant participé à la performance en savonnant le dos de la jeune fille pouvaient se voir remettre un tuyau en bambou qui leur permettait de plonger leur regard dans l'eau du bain, et les gratifiait du privilège de voir - ou du moins d'essayer, et cette incertitude est à la base du jeu - le corps immergé, par delà la mousse; HirookA Keiichi 広岡敬一, op. cit., 1993, p. 25. 
164 Cahiers d'études japonaises n²1

un cap lorsque des spectateurs sont appelés à prendre part au spectacle sur scène avec divers accessoires, lors de namaita shō ナマ板シ $\exists-{ }^{73}$. Au même titre que le bed show, la sexualité sous les projecteurs est une formule déclinable à l'envi. Ainsi les daburu shirokuro shō W白黒ショー, mobilisant quatre personnes, et autres gaijin manaita shō 外人マナ板ショ - mettant en scène des personnes non japonaises, investissent les salles de striptease le long des années 1970. Dès lors, le striptease ne connaîtra plus d'évolution notoire, et la documentation à son propos se fait plus discrète à mesure que nous nous rapprochons des années 1990.

\section{Conclusion : éléments pour une stripologie}

Tableaux vivants, liberal shows, théâtres-striptease, bed shows, « performances spéciales » ou namaita : les métamorphoses et leurs nombreux avatars qui jalonnent l'histoire du striptease au Japon ont suscité auprès des commentateurs divers types de réactions. Parmi les plus notoires, il faut mentionner une certaine nostalgie, ainsi qu'une tendance à anticiper le déclin du striptease ${ }^{74}$. Il est vrai que les changements s'opèrent en majeure partie sans appel, et que les spectacles de nus ne reproduisent en principe jamais un modèle ancien, éculé. Ainsi les revues burlesques d'Asakusa, les gakubuchi, nyūyoku, kinpatsu nūdo, etc. ont tous bel et bien disparu. Les théâtres-striptease ont en un sens été dépouillés de leurs musiciens, de leurs comiques et de leurs librettistes, à mesure que le caractère sexuel des performances s'intensifiait. Il nous paraît toutefois erroné de n'envisager ces évolutions que comme des soustractions, motivées par le profit ou commandées par la « décadence des mœurs ». En effet, il ne faut pas perdre de vue que ce glissement vers le sex show ne correspond pas à une épuration du numéro d'effeuillage, dans

73. Il s’agit de la verlanisation de mana ita まな板, la planche à découper les aliments. Un jeu de mot pourrait être à l'origine de l'inversion nama ita, où nama 生 (《cru », 《 frais ») signifierait peut-être « en direct », sur les planches.

74. Ozawa Shōichi 小沢昭一, Fukai Toshihiko 深井俊彦, NAKatani Akira 中谷陽, op. cit., 1973, p. 102. En France, Nelly Kaplan prophétisait à la veille des années 1960 : «"Quand sera brisé l'infini servage de la femme", le strip-tease, comme spectacle public, s'éteindra sûrement de lui-même. »; «Le Striptease : fin de l'enquête », in André Breton (dir.), op. cit., 1958, p. 58. 
la mesure où exhibition de la vulve, caresses et attouchements viennent en réalité s'y ajouter. Ces éléments viennent donc en plus du striptease. Quoi qu'il en soit, l'obsolescence des modes et le refus de revenir à des formes dépassées semblent, à l'usure, avoir eu raison de cette dynamique de l'innovation. Avec le recul, nous pouvons constater que cette course au renouveau s'essouffle peu après l'apparition des namaita, à partir desquels le striptease peine à faire peau neuve.

L'épuisement du renouvellement formel ne sonne cependant pas le glas du striptease dont l'industrie prospère encore au début des années $1980^{75}$. Cette époque coïncide avec l'avènement des premières cabines de peep-shows ${ }^{76}$, mais aussi et surtout avec l'émergence et le fulgurant développement du marché des vidéocassettes pornographiques (AV, pour Adult Video $)^{77}$. En termes de contenu, les images proposées entretiennent indéniablement un air de famille avec les manifestations du striptease telles que nous les avons vues dans les années 1970. Les dispositifs en jeu diffèrent toutefois considérablement. En effet, à la différence de la salle de striptease qui, malgré ses dimensions parfois modestes ${ }^{78}$, n'isolait le spectateur que par la relative pénombre dont il était enveloppé, le peep-show propose un espace authentiquement privatif. Le client peut ainsi, dans l'intimité de sa

75. Le pic de six cent soixante-quinze établissements proposant des spectacles de nu est atteint en 1985 (la moitié environ sont des théâtres-striptease). Il ne va dès lors cesser de décroître ; KADOKURA Takashi 門倉貴史, Bakuhatsu suru chika bijinesu 爆発する地 下ビジネス (L'explosion de l'industrie souterraine), Tōkyō, PHP kenkyūjo PHP研究 所, 2007, p. 123. Lors de l'entretien qu'il nous accorda, Hara Yoshiichi 原芳市 déclarait qu'il y avait alors une quarantaine d'établissements consacrés au striptease au Japon, dont une demi-douzaine à Tōkyō.

76. Selon Hirooka Keiichi 広岡敬一, le premier nozokibeya 司見き部屋 (peep-show) ouvre ses portes à Ōsaka en février 1981; HrRooka Keiichi 広岡敬一, Sengo seifüzoku taikei 戦後性風俗大系 (Recueil des mœurs sexuelles d'après-guerre), Tōkyō, Shōgakukan 小 学館, 《Shōgakukan bunko »小学館文庫, 2007, p. 314.

77. La cassette vidéo, plus que le cinéma, joua un rôle crucial dans la diffusion de films pornographiques indigènes; FUJIKI TDC 藤木TDC, Adaruto bideo kakumei-shi アダ ルトビデオ革命史 (Histoire de la révolution des vidéocassettes pour adultes), Tōkyō, GS Gentōsha shinsho GS幻冬舎新書, 2009, p. 39-66.

78. Les nūdo sutajio ヌードスタジオ (nude studios), échoppes dans lesquelles le client se voyait remettre un appareil photo (parfois sans même de pellicule) avec lequel il se plaisait à « photographier » des jeunes filles en petite tenue, étaient tout particulièrement réputés pour leur exiguïté. 
166 Cahiers d'études japonaises n²1

cabine, assister solitairement au spectacle qui se produit devant lui, à l'extérieur. La cassette vidéo quant à elle amène une expérience d'un temps radicalement différé. Le spectateur n'ayant accès qu'au déroulement d'images déjà enregistrées (tout comme au cinéma), la distance regardant/regardé devient irréductible : le support substitue à chaque regardé une machine et abolit de la sorte toute possibilité d'échange et de réciprocité. Le magnétoscope de salon implique en revanche des procédures d'interactions avec la machine, que la salle de cinéma refuse en principe à ses spectateurs. Celui-ci se retrouve à même de contrôler le flux des images. En d'autres termes, l'objet de désir est désormais disponible au moment souhaité. Plus, la vidéo affranchit dans une certaine mesure le spectateur du poids de son moi social. Les images sont aveugles et ne portent pas de jugement. Le dispositif machinique intensifie l'intimité des représentations et invite son regardant à plonger dans l'anonymat, à épancher sa soif scopophile et jouir de ce retrait du monde. L'expérience du temps que le spectateur fait au striptease se rapproche quant à elle du temps physique, collectivement vécu. Nous retrouvons ici cette dimension éminemment sociale du striptease, que les progrès technologiques nous incitent à concevoir dorénavant comme consubstantielle à l'effeuillage. L'industrie audiovisuelle pornographique ne se présente donc pas exactement comme concurrente du striptease, car leurs modes d'expressions respectifs diffèrent considérablement. De fait, la pratique de cet art vivant qu'est l'effeuillage se perpétue encore de nos jours $^{79}$. Si la concomitance de l'expansion du marché AV dans la seconde moitié des années 1980 et de la fermeture de nombreuses salles de striptease paraît conforter la thèse de la rivalité, la présence répétée de stars du X sur les planches tend en revanche à indiquer une certaine forme de complicité qui pourrait marquer les manifestations les plus récentes ${ }^{80}$.

79. Les recueils de photographies Za sutorippā de Hara Yoshiichi 原芳市 permettent de se faire une idée assez juste du striptease japonais de ces dernières années.

80. Le Rokku-za accueillait ainsi deux stars réputées du X en automne 2011, Ayumu あ ゆむ et Ozawa Maria 小澤マリア. 
Quoique fort distincts ${ }^{81}$, striptease, pornographie et prostitution partagent une même odeur de soufre au sein de l'opinion publique, si bien que le striptease, et plus généralement les danses de nu, ont habituellement mauvaise presse, au Japon comme ailleurs. Au-delà de la nudité elle-même, la question de l'univers auquel elle renvoie - établissement, quartier mais aussi personnes et mours - n'est de toute évidence pas étrangère à l'opprobre qui frappe le striptease. Il est en effet probable que le nô nu monté par Takechi Tetsuji 武智鉄二 en 1956 se serait heurté aux mêmes virulentes critiques si les effeuilleuses avaient été « convenablement 》 vêtues. Une comparaison de divers témoignages relatifs au striptease, provenant des trois aires culturelles dans lesquelles il jouit d'une forte popularité, révèle cependant une réception sensiblement différente en fonction des régions. Aux États-Unis, le striptease connaît toujours un grand succès. La Cour suprême a d'ailleurs reconnu les danses de nu comme une forme d'expression protégée par le Premier amendement en 1991, soit près d'un siècle après leurs premiers pas sur la scène des théâtres américains $^{82}$. La fin du $\mathrm{Xx}^{\mathrm{e}}$ siècle a en outre vu la publication d'études et enquêtes

81. Diverses catégories existent dans la définition et la gestion du commerce sexuel au Japon. Théâtres-striptease, nūdo sutajio, peep-shows et cabines de visionnage de vidéos appartiennent tous à la même, celle des établissements à caractère sexuel de troisième catégorie (seifüzoku kanren tokushu eigyō sangō eigyō 性風俗関連特殊営業・3号 営業), et sont donc clairement distingués par le droit japonais d'autres commerces tels que soap lands ou sex shops (respectivement première et cinquième catégories); ManAKa Toshimitsu 間中利光, KIjIma Yasuo 木島康雄, Hosuto kurabu kyabakura kaiten kaigyō tetsuzuki kanzen gaido - zukai to shinsei shorui kisairei tsuki ホストクラ ブ・キャバクラ開店・開業手続き完全ガイドー図解と申請書類記載例付き (Guide complet pour ouvrir un host club ou un cabaret : illustrations et formulaires d'enregistrement types fournis), Tōkyō, Sanshūsha 三修社, 2008, p. 10-13.

82. Clinton P. Hansen, “To Strip or Not to Strip: The Demise of Nude Dancing and Erotic Expression Through Cumulative Regulations”, Valparaiso University Law Review, vol. 35, nº 3, Valparaiso, Valparaiso University School of Law, 2001, p. 562. 


\section{CIPANGO}

168 Cahiers d'études japonaises n²1

sérieuses sur l'effeuillage américain ${ }^{83}$. La situation n'est pas tout à fait identique en Europe, où les milieux intellectuels ont plutôt tendance à mépriser cet art scénique. On ne compte sur les cinquante dernières années qu'une poignée d'ouvrages qui lui sont consacrés, parmi lesquels toutefois, à côté des rares ouvrages spécialisés (et pas toujours très inspirés), des travaux d'intellectuels de renom : Barthes, Eco, ou encore le groupe surréaliste de Breton. Force est de constater cependant que ces derniers ne se sont guère attachés à y voir un véritable objet d'étude, et que leurs essais oscillent entre un amusement gentiment complice ${ }^{84}$, une circonspection teintée d'incompréhension $^{85}$, ou une virulente aversion ${ }^{86}$. Le cas japonais est en revanche fort différent. Bien que les critiques négatives aient également été abondantes, de nombreux artistes et intellectuels traitent du striptease assez tôt. C'est également le cas d'acteurs du monde du nu, ou encore de nombreux photographes qui s'intéressent à l'effeuillage et en retracent les évolutions dans leurs albums. Il existe ainsi en japonais

83. Les études sont très diverses, pas toujours laudatives, et parfois pour le moins inattendues. Ainsi, selon le rapport de la police du comté de Fulton (Géorgie, États-Unis) qui a analysé durant deux années et demie (1995-1997) les liens qui pouvaient exister entre consommation d'alcool, boîtes de striptease et délinquance, le constat est sans appel : les établissements proposant de l'alcool à leurs clients (bar, etc.) mais pas de show de striptease connaissent plus de crimes et de troubles à l'ordre public que ceux qui allient alcool et effeuillage (il convient toutefois de préciser que l'étude est basée sur le nombre d'appels relatifs à des plaintes reçus par les services de police, et non sur le nombre véritable d'infractions). L'étude a été citée en 2001 dans un procès opposant plusieurs établissements proposant de tels services au comté de Fulton. Voir Judith Lynne Hanna, "Dance under the Censorship Watch", Journal of Arts Management, Law, and Society, vol. 31, nº 4, Washington D.C., Heldref Publications, 2002, p. 308 et 316.

84. Umberto Eco, «Platon au Crazy Horse », in Pastiches et postiches, Paris, 10/18, 1996, p. 55-59.

85. Roland Barthes, « Striptease », in Mythologies, Paris, Seuil, « Points - Essais », 2007, p. 137-140.

86. Michèle Perrein, «Une enquête sur le striptease », in André Breton (dir.), op. cit., 1958, p. 56-63 ; «Le Striptease : fin de l'enquête », in André Breton (dir.), Le Surréalisme, même, vol. 5, Paris, J.-J. Pauvert, 1959, p. 56-60 ; Gérard Legrand, « La philosophie dans le saloon », ibid., p. 60-62. Quelques avis, pour la plupart écrits par des femmes, sont toutefois un peu plus nuancés. 
une copieuse bibliographie consacrée au striptease, et ce dès la fin des années $1940^{87}$. Par ailleurs, nous avons pu noter la parution de publications régulières consacrées à l'effeuillage ${ }^{88}$, ainsi que la production d'émissions, à une date très précoce ${ }^{89}$.

Le striptease est un art de la scène, et la « nudité », nous l'avons vu, ne représente - pour un temps du moins - pas un objectif, une fin en soi. De même qu'au théâtre, plus peut-être, la parure (costumes, bijoux, etc.) joue un rôle primordial. Pour Jean Baudrillard, l'absence de parure est toute relative, puisque jamais totale ${ }^{90}$. Plus nuancée, la sociologue Ueno Chizuko 上野千鶴子 avance que :

Le butterfly de la stripteaseuse n'est là que pour être finalement ôté. Avant d'être ôté, il n'est là que pour affirmer que le sexe est là.

87. La presse quotidienne semble en revanche s'être totalement désintéressée de ce sujet. Ainsi l'Asahi shinbun qui, depuis 1945, n'a consacré que peu d'articles à cette activité, et souvent sous un aspect lié à l'urbanisme ou à la sécurité publique (théâtre-striptease s'installant à proximité d'une école, incendie d'un établissement, etc.).

88. Par exemple les revues Nüdo interijensu ヌード・インテリジェンス (Nude Intelligence), Play Ana, Pussy プッシー, Striptease de Japon, etc. Celles-ci sont cependant difficilement accessibles et nous n'avons pu les consulter. Bien qu'elles aient disparu, la revue Shükan taish ū 週刊大衆 proposait il y a quelques années encore chaque semaine une chronique dédiée à l'effeuillage, « Maihime densetsu » 舞姫伝説 (Légendes d'almées), tenue par Hara Yoshiichi 原芳市.

89. L'actuelle chaîne de télévision TBS programma par exemple en 1955 une émission consacrée au music hall qui fit la part belle à l'effeuillage; ArAmaTA Hiroshi 荒俣宏, op . cit., 2000, p. 217-218.

90. En effet, quel que soit le degré de nudité atteint par l'effeuilleuse, elle ne peut jamais être considérée comme «nue », au sens strict du terme : elle conservera toujours un accessoire ou vêtement tel que ses chaussures, un bijou, une perruque, sans parler du maquillage. Il s'agit là d'un caractère d'affirmation du sexe et même de séduction qui, comme le rappelle Baudrillard, «n'est jamais de l'ordre de la nature, mais de celui de l'artifice - jamais de l'ordre de l'énergie, mais de celui du signe et du rituel » (Jean BAUDRILlard, op. cit., 1992, p. 10). Il ajoute plus loin : « Pour qu'il y ait sexe, il faut que les signes redoublent l'être biologique », et la remarque s'applique fort bien au striptease (ibid., p. 26). Dans un registre plus léger, Le Rire affichait à la fin du XIX ${ }^{\mathrm{e}}$ siècle une illustration présentant un dessinateur venu proposer ses créations à un éditeur (en première page du journal). Ce dernier s'exclamant, en réaction au dessin qui lui est présenté : « Voyons, monsieur, dans quel monde avez-vous pu voir que les femmes nues n'ont pas de bas ?!! »; illustration de J.-L. Forain, Le Rire - Journal humoristique paraissant le samedi, n 157, Paris, 6 novembre 1897, p. 1 (nous remercions Yves Riquet de nous en avoir signalé l'existence). 


\section{CIPANGO}

S'il ne cachait pas pour dévoiler, le butterfly n'aurait aucun sens.

ストリッパーのバタフライは、ただ最後にそれを取り 去るためだけにある。それを取り去る前に、性器がそこ にあることを、誇示するためだけにある。あらわすため に隠すのでなければ、バタフライには何の意味もない91。

N'excluant pas l'idée d'une nudité « totale », elle rejoint néanmoins Baudrillard peu après lorsqu'elle écrit : « Ce que le butterfly signifie n'est pas une fonctionnalité, mais un symbole. $\gg^{92}$ En d'autres termes, l'utilité première de la tenue s'estompe, au profit d'une fonction ornementale et signifiante. Le psychanalyste Béla Grunberger avance même l'idée que «l'essence du striptease paraît résider dans "l'effeuillage" successif des divers symboles péniens dont la femme s'est affublée (longs gants noirs, bas noirs, chaussures à talons ou bottines, corset, etc.), comme si l'intérêt de la chose ne résidait pas dans le fait que la femme porte un pénis ni dans sa nudité, mais dans sa castration progressive et multiple ${ }^{93}$. De manière plus pragmatique, nous pouvons affirmer que la « nudité » est une notion dont l'acception comme l'acceptabilité sont pour le moins fluctuantes. Qu'il s'agisse, dans le cas du striptease, d'un argument de vente majeur nous paraît indiscutable, en témoigne le nombre de performances à promettre $\mathrm{du}$ « nu ». Cependant, et en dépit de son caractère promotionnel, la « nudité » proposée sur les scènes dépasse le leurre. Les stripteaseuses ne simulent pas leur déshabillage, mais y procèdent bel et bien, couche par couche, jusqu'à la limite de ce que l'époque conçoit comme « nudité ». Dans le même ordre d'idée, il est intéressant d'observer que la danse seins nus n'est, à partir de 1977, plus assimilée à du striptease ${ }^{94}$.

91. UENo Chizuko 上野千鶴子, Sukāto no shita no gekijō スカートの下の劇場 (Le théâtre de sous la jupe), Tōkyō, Kawade shobō shinsha 河出書房新社, « Kawade bunko » 河出文庫, 1992, p. 17.

92. バタフライが意味しているものは、機能性ではなく、シンボル性です； ibid., p. 42.

93. Béla Grunberger, «De l'image phallique », Revue française de psychanalyse, tome XXVIII, nº 1, Paris, PUF, 1964, p. 224.

94. OKa Yōichi 丘陽一, «'77 Kantō sutorippu hakusho »'77関東ストリップ白書 (Livre blanc du striptease 1977), Geinō tōzai - Sutorippu dai tokushū 藝能東西一ス卜 リップ大特集, op. cit., 1977, p. 52-57. 
Le mouvement de déclin amorcé à l'entame des années 1980 n'a fait que se confirmer depuis. Cependant, et bien que ténue, la présence du striptease dans le paysage japonais n'en demeure pas moins réelle. Nombre des rôles qui étaient les siens - de la «zone neutre » de l'immédiat après-guerre aux extrémités voyeuristes des années 1970 - ont, depuis, trouvé à s'exprimer en d'autres lieux ou de manière différente ; ce qui ne laisse cependant pas de s'interroger sur les raisons de sa pérennité. Le striptease a traversé les années, parvenant à se forger une place qui lui est propre. Et, comme nous l'avons vu, il ne semble plus guère vouloir poursuivre une guerre $\mathrm{du}$ « toujours plus », depuis longtemps perdue.

À l'écart du monde, hors du temps - du temps présent tout du moins - le striptease semble désormais regarder en arrière. Dénué des différents avatars qui ont jalonné son parcours, loin des folles messes des années 1970, il n'a finalement évolué que pour se rapprocher de ce qui avait fait ses grandes heures, et trouve désormais à s'exprimer sous une forme simple qui aura longtemps semblé trop évidente : l'effeuillage. Baignée de lumière, la danseuse s'épluche en rythme, pour finalement poser au centre de la scène. On le sait : la nostalgie n'est pas preuve de créativité, mais elle a pour elle l'efficacité. Au-delà du retour formel à des spectacles qui évoquent les pantomimes séductrices des années 1950-1960, et bien que le souvenir du temps passé n'habite pas chacun de ces shows, une simple visite dans un thêâtre-striptease permettra de s'en convaincre : les spectacles jouent à plein sur la nostalgie de l'ère Shōwa, notamment par l'utilisation de costumes et musiques faisant songer aux années de l'après-guerre. Jusqu'aux accessoires, désuets au possible, qui évoquent les spectacles de bric et de broc d'une époque en pleine reconstruction, aujourd'hui bien lointaine. Ainsi, les appels du pied faits aux jeunes générations - par l'utilisation de musiques actuelles, de stars du cinéma porno, parfois même de réductions offertes aux seniors, étudiants et couples ! - semblent de bien timides tentatives de s'inscrire dans la durée. Un parti pris qui se reflète dans la moyenne d'âge, respectable, des spectateurs. De fait, le striptease japonais est, peut-être, condamné à disparaître avec ces derniers. 


\section{CIPANGO}

172 Cahiers d'études japonaises n²1

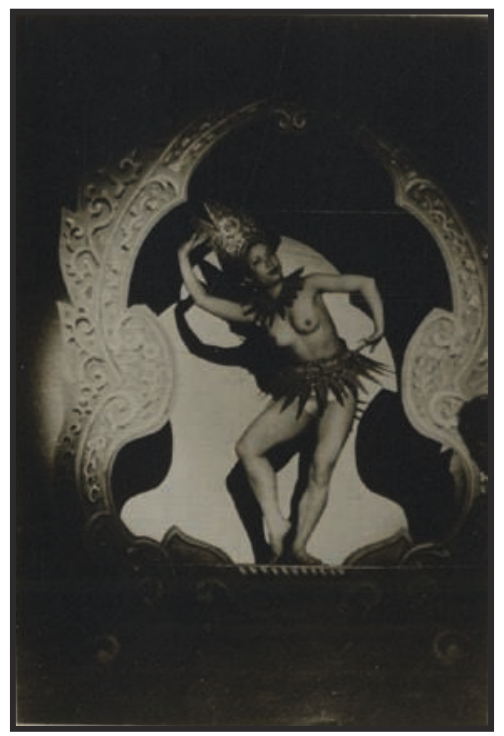

FIGURE 1 .

Gakubuchi shō au cinquième étage du Teitōza à Tōkyō, avril 1947. Il s'agit très probablement de Kataoka Mari 片岡マリ. Source : auteur anonyme, collection Enpaku, Waseda

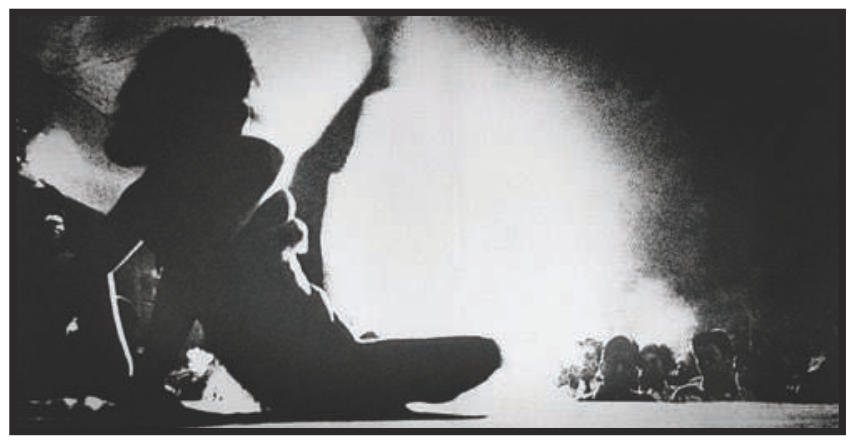

FIGURE 2.

Finale d'un show dans un théâtre-striptease de Kanagawa, 1966.

Source : Moriyama Daidō 森山大道 


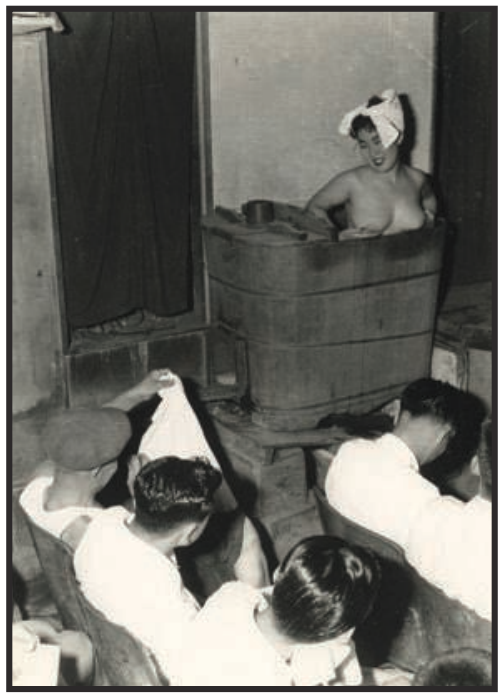

FIGURE 3.

《Asakusa no sutorippu gekijō ni okeru nyūyoku-shō» 浅草のストリップ劇場に おける入浴ショー (Nyūyoku shō dans un théâtre-striptease d'Asakusa), entre 1951 et 1955. Source : Hirooka Keiichi 広岡敬一

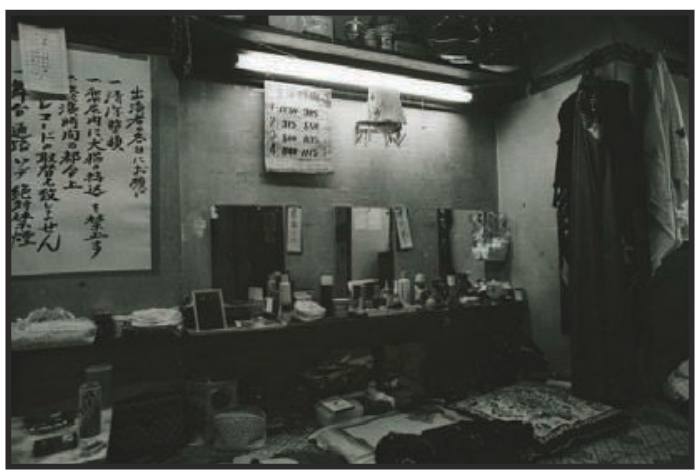

FIGURE 4.

Loge des danseuses dans un théâtre-striptease, 1977. Sont indiqués les horaires des quatre représentations, de $12 \mathrm{~h} 30$ à $23 \mathrm{~h} \mathrm{15}$, ainsi que les règles à observer dans l'enceinte du théâtre. Source : Hara Yoshiichi 原芳市 


\section{CIPANGO}

174 Cahiers d'études japonaises $n^{\circ} 21$

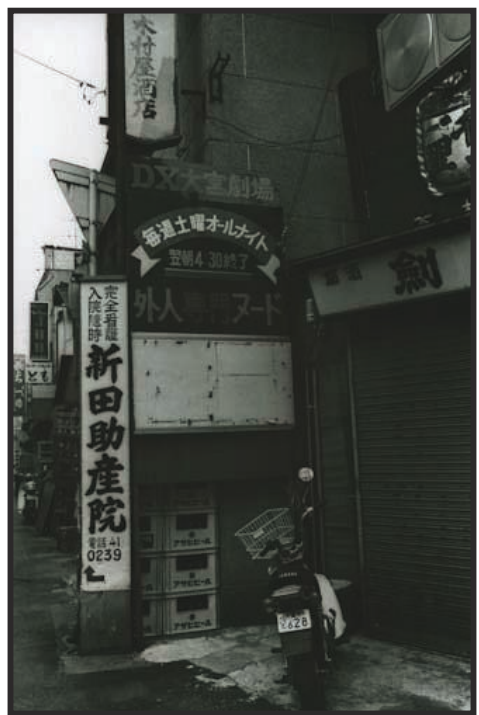

FIGURE 5.

Enseigne d'un théâtre spécialisé dans les gaijin nūdo shō, le DX Ōmiya gekijō DX大 宮劇場 (département de Saitama). Source : Hara Yoshiichi 原芳市

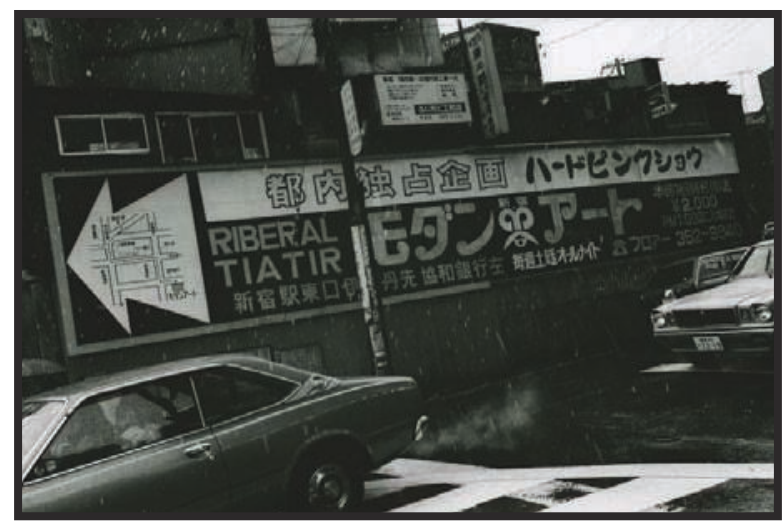

FIGURE 6.

Publicité pour le Modan Āto モダンアート (Modern Art), théâtre-striptease situé à Shinjuku dans les années 1970. Source: Hara Yoshiichi 原芳市 


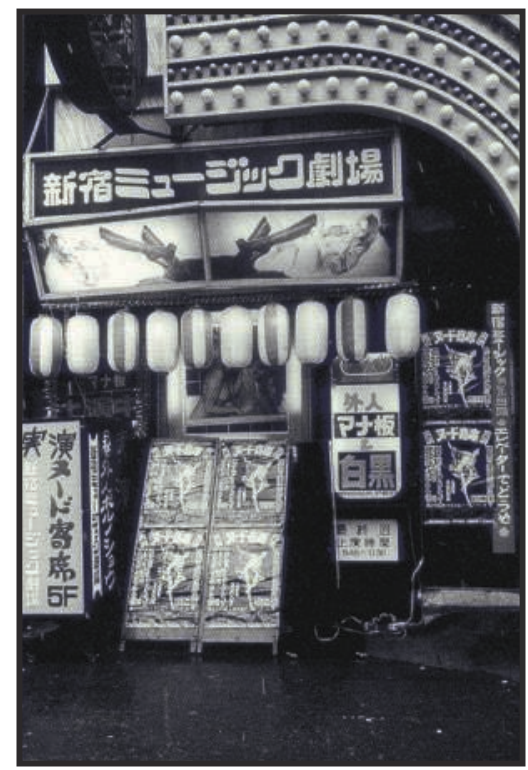

FIGURE 7.

Devanture du Shinjuku myūjikku gekijō 新宿ミュージック劇場 dans les années 1970. Sont annoncés les différents spectacles proposés par l'établissement, gaijin manaita et shirokuro. Source : Hara Yoshiichi 原芳市

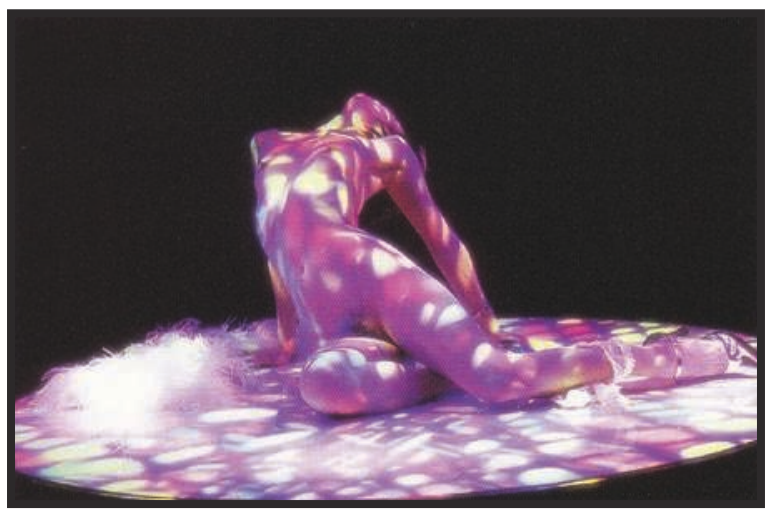

FIGURE 8.

Finale d'un show à l'Asakusa Rokkuza 浅草ロック座 dans les années 1990. Source : Hara Yoshiichi 原芳市 


\section{CIPANGO}

176 Cahiers d'études japonaises n²1

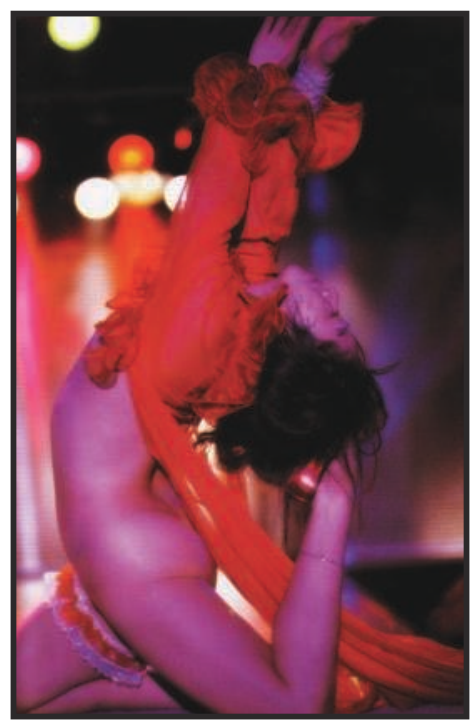

FIGURE 9.

Finale d'un show à l'Asakusa Rokkuza 浅草ロック座 dans les années 1990.

Source : Hara Yoshiichi 原芳市

\section{Bibliographie}

\section{Ouvrages et revues}

Allais Alphonse, Rose et Vert-Pomme (cuvres anthumes), Paris, Paul Ollendorff, $1894,330 \mathrm{p}$.

Aramata Hiroshi 荒俣宏, Banpaku to sutorippu 万博とストリップ (Expositions universelles et striptease), Tōkyō, Shūeisha shinsho 集英社新 書, 2000, $238 \mathrm{p}$.

Asai Shōji 浅井昭治, Tsurumi Shunsuke 鶴見俊輔, Nihon no taishū geijutsu 日本の大衆芸術 (Arts populaires du Japon), Tōkyō, Kyōyō bunko 教養文 庫, 1962 , 468 p. 
Barthes Roland, Essais critiques, Paris, Seuil, 1981, 275 p.

Barthes Roland, Mythologies, Paris, Seuil, « Points - Essais », 2002, 275 p.

Bataille Georges, L'Érotisme, Paris, Éditions de Minuit, 2011, 284 p.

Baudrillard Jean, De la séduction, Paris, Gallimard, « Folio », 1992, 247 p.

Baudrillard Jean, L'Échange symbolique et la mort, Paris, Gallimard, «Bibliothèque des sciences humaines », 1976, 347 p.

Banham Martin, The Cambridge Guide to Theater, Cambridge, Cambridge University Press, 1995, 1233 p.

Breton André (dir.), Le Surréalisme, même, vol. 4, Paris, printemps 1958, 64 p.

Breton André (dir.), Le Surréalisme, même, vol. 5, Paris, printemps 1959, 64 p.

Charvil Jean, Histoire et sociologie du striptease, Paris, Éditions Planète, 1969, $344 \mathrm{p}$.

Chevalier Denys, Métaphysique du striptease, Paris, J.-J. Pauvert, 1960, 210 p.

Des Aulnoyes François, Histoire et philosophie du striptease : essai sur l'érotisme au music-hall, Paris, Pensée moderne, 1957, 100 p. +85 pl.

Dower John W., Embracing Defeat: Japan in the Wake of World War II, New York, W.W. Norton \& Co. - The New Press, 1999, 676 p.

Eco Umberto, Pastiches et postiches, Paris, 10-18, 1996, 184 p.

FUJIKI TDC 藤木TDC, Adaruto bideo kakumei-shi アダルトビデオ革命 史 (Histoire de la révolution des vidéocassettes pour adultes), Tōkyō, GS Gentōsha shinsho GS幻冬舎新書, 2009, 263 p. 


\section{CIPANGO}

178 Cahiers d'études japonaises n²1

Geinō tōzai - Sutorippu dai tokushū 藝能東西ーストリップ大特集 (Geinō tōzai : grand numéro spécial sur le striptease), Tōkyō, Atarashii Geinō kenkyūshitsu 新しい芸能研究室, 1977, 248 p.

Hara Yoshiichi 原芳市, Sutorippu no aru machi-ekizotikku shō no sekai wo tanoshimu ストリップのある街ーエキゾティック・ショーの世界を楽し む (Quartiers de striptease : jouir du monde des shows exotiques), Tōkyō, Jiyū kokuminsha 自由国民社, 1999, 127 p.

HARA Yoshiichi 原芳市, Za sutorippā-maibime densetsu gojūnin ザ・ストリ ッパーー舞姫伝説50人 (The stripper : cinquante légendes de danseuses), Tōkyō, Futabasha 双葉社, 2000a.

HARA Yoshiichi 原芳市, Za sutorippā 2 - maibime densetsu rokujūninin ザ・ ストリッパーー舞姫伝説62人 (The stripper 2 : soixante-deux légendes de danseuses), Tōkyō, Futabasha 双葉社, 2000b.

HirookA Keiichi 広岡敬一, Sengo seifüzoku taikei 戦後性風俗大系 (Recueil des mœurs sexuelles d'après-guerre), Tōkyō, Shōgakukan 小学館, «Shōgakukan bunko » 小学館文庫, 2007, 397 p.

Hirooka Keiichi 広岡敬一, Sutorippu bojō-Asakusa, Yoshiwara romanesuku ストリップ慕情ー浅草・吉原ロマネスク (La nostalgie du striptease : Asakusa, Yoshiwara romanesque), Tōkyō, Kōdansha 講談社, « Kōdansha bunko » 講談社文庫, 1993, 240 p.

Inoue Hisashi 井上ひさし, Asakusa Furansu-za no jikan 浅草フランス座の 時間 (Au temps de l'Asakusa Furansu-za), Tōkyō, Bunshun nesuko 文春礻 スコ, 2001, 254 p.

InOue Hisashi 井上ひさし, Isamu yori yoroshiku イサムよりよろしく(T'as le bonjour d'Isamu), Tōkyō, Bunshun bunko 文春文庫, 1976, 253 p.

IsHIKAWA Hiroyoshi 石川弘義 (dir.), Taishū bunka jiten 大衆文化辞典 (Encyclopédie de la culture populaire), Tōkyō, Kōbundō 弘文堂, 1991, 1048 p. 
KADOKURA Takashi 門倉貴史, Bakuhatsu suru chika bijinesu 爆発する地下ビ ジネス (L'explosion de l'industrie souterraine), Tōkyō, PHP kenkyūjo PHP 研究所, 2007, 228 p.

Kawamoto Kōji 川本耕次, Poruno zasshi no shōwa-shi ポルノ雑誌の昭 和史 (Histoire de l'ère Shōwa par les magazines pornographiques), Tōkyō, Chikuma shobō 筑摩書房, «Chikuma shinsho »ちくま新書, 2011, 205 p.

Kitano Takeshi 北野武, Asakusa Kid, Paris, le Serpent à plume, « Motifs », $2001,260 \mathrm{p}$.

Koyanagi Shōsuke 小柳詳助, Jì sutoringu no Maria - Jipushī Rōzu burū nōto G 線上のマリアージプシー・ローズ・ブルーノート (Maria on G-string: Gypsie Rose Blue Note), Tōkyō, Gendai-shi shuppankai 現代史出 版会, 《Tokuma shoten 》徳間書店, 1982, 253 p.

Koyano Atsushi 小谷野敦, Nihon no baishunshi-yükō jofu kara sōpu rando made 日本の売春史一遊行女婦からソープランドまで (Histoire de la prostitution au Japon : des amuseuses itinérantes au soap land), Tōkyō, Shinchōsha 新潮社, 2007, $234 \mathrm{p}$.

ManaKa Toshimitsu 間中利光, KiJima Yasuo 木島康雄, Hosuto kurabu kyabakura kaiten kaigyō tetsuzuki kanzen gaido - zukai to shinsei shorui kisairei tsuki ホストクラブ・キャバクラ開店・開業手続き完全ガイドー図 解と申請書類記載例付き (Guide complet pour ouvrir un host club ou un cabaret : illustrations et formulaires d'enregistrement types fournis), Tōkyō, Sanshūsha 三修社, 2008, 245 p.

NAGAI Kafū 永井荷風, Danchōtei nichijōo 断腸亭日乗 (Journal de Danchōtei), Tōkyō, Iwanami shoten 岩波書店, 《Iwanami bunko » 岩波文庫, 1987, $427 \mathrm{p}$.

NAGAI Kafū 永井荷風, Zenshū dai nijū-hachi kan 全集第二十八巻 (CEuvres complètes, tome 28), Tōkyō, Iwanami shoten 岩波書店, 1994, 587 p. 


\section{CIPANGO}

180 Cahiers d'études japonaises $n^{\circ} 21$

Ogura Takayasu 小倉孝保, Shodai Ichijō Sayuri densetsu - Kamagasaki ni chitta bara 初代一条さゆり伝説一釜ヶ崎に散つたバラ (Légende d’Ichijō Sayuri première du nom : la rose qui dépérit à Kamagasaki), Ōsaka, Yōbunkan shuppan 葉文館出版, 1999, 238 p.

Ozawa Shōichi 小沢昭一, Ozawa Shōichi zadan 1 - Jinruigaku nyūmon Oasobi to gei to 小沢昭一座談1 一人類学入門一お遊びと芸と (Causeries avec Ozawa Shōichi, 1 : introduction à l'anthropologie : le divertissement et l’art), Tōkyō, Shōbunsha 晶文社, 2007, 334 p.

Ōzasa Yoshio 大笹吉雄, Nihon gendai engeki-shi - Shōwa sengo-hen 日本現 代演劇史一昭和戦後篇 (Histoire du théâtre contemporain au Japon : la période Shōwa après-guerre), vol. 1, Tōkyō, Hakusuisha 白水社, 1998, 928 p.

Sharp Jasper, Behind the Pink Curtain: the Complete History of Japanese Sex Cinema, Surrey, Fab press, 2008, 415 p.

ShteIr Rachel, Striptease: The Untold History of the Girlie Show, New York, Oxford University Press, 2004, 438 p.

Shimokawa Kōshi 下川耿史, Nihon eroshashin-shi 日本エロ写真史 (Histoire

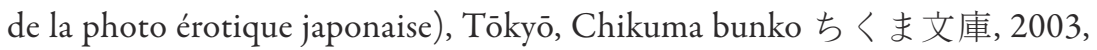
$218 \mathrm{p}$.

Shingeki - tokushū sutorippu 新劇一特集ストリップ (Shingeki : numéro spécial sur le striptease), nº 9, Tōkyō, Hakusuisha 白水社, 1973, 144 p.

Shiota Masaru 塩田勝 (dir.), Ryūkōgo ingo jiten 流行語 - 隠語辞典 (Dictionnaire de parler populaire et d'argot), Tōkyō, San.ichi shobō 三一書 房, $1981,276 \mathrm{p}$.

Shōwa nimannichi no zenkiroku, Dai 7 kan - Haikyo kara no shuppatsu, Shōwa 20 nen-21 nen 昭和二万日の全記録・第7巻一廃噓加らの出発・昭和 20年～21年 (Chroniques des 20000 jours de l'ère Shōwa, tome 7 : le départ à 
partir des ruines, années 1945-1946), Tōkyō, Kōdansha 講談社, 1989, 340 p. [cité $S N N Z$, vol. 7 dans les notes]

Shōwa nimannichi no zenkiroku, Dai 8 kan - Senryōka no minshushugi, Shōwa 22 nen-24 nen 昭和二万日の全記録 - 第8巻一占領下の民主主義 - 昭 和22年～24年 (Chroniques des vingt mille jours de l'ère Shōwa, Tome $8:$ la démocratie sous l'occupation, années 1947-1949), Tōkyō, Kōdansha 講談社, 1989, 358 p. [cité $S N N Z$, vol. 8 dans les notes]

Tanaka Komimasa 田中小実昌, Vinasu no ekubo - Tanaka Komimasa sakubinshū ヴィーナスのえくぼー田中小実昌作品集 (Les fossettes de Vénus : recueil des œuvres de Tanaka Komimasa), vol. 1, Tōkyō, Shakai shisōsha 社会思想社, 1990, 341 p.

TANAKa Komimasa 田中小実昌, Gakuyabanashi - Itoshi no Jipushi Rōzu to odorikotachi＼cjkstart楽屋ばなしーいとしのジプシー・ローズと踊り子たち (Récits de loges : Gipsy Rose et danseuses chéries), Tōkyō, Bungei shunjū 文 藝春秋, 1992, $214 \mathrm{p}$.

The Za, no 3 - Nipponjin no heso tokushu, Nihon no odorikotachi The 座 $\mathrm{n}^{\circ} 3-$ 日本人のへそ特集・日本の踊り子たち (The Za, nº 3 : numéro spécial nombrils nippons, danseuses du Japon), Tōkyō, Komatsu-zaこまつ座, 1985, $124 \mathrm{p}$.

Tschudin Jean-Jacques, Hamon Claude (dir.), La Modernité à l'horizon, Arles, Philippe Picquier, 2004, 244 p.

Tsurumi Shunsuke 鶴見俊輔, SATō Tadao 佐藤忠男, KITA Morio 北杜夫 (dir.), Manga sengoshi 漫画戦後史 (Histoire des mangas de l'après-guerre), vol. 15, nº 2, Tōkyō, Chikuma Shobō 筑摩書房, « Gendai manga » 現代漫 画, 1970, $330 \mathrm{p}$.

UENo Chizuko 上野千鶴子, Sukāto no shita no gekijō スカートの下の劇場 (Le théâtre de sous la jupe), Tōkyō, Kawade shobō shinsha 河出書房新社, « Kawade bunko » 河出文庫, 1992, 215 p. 
182 Cahiers d'études japonaises n²1

Wilmeth Don B., The Cambridge Guide to American Theater, Cambridge, Cambridge University Press, 2007, 757 p.

Wortley Richard, A Pictorial History of Striptease, London, Octopus, 1976, $160 \mathrm{p}$.

\section{Articles et chapitres d'ouvrages}

Aldridge A. Owen, "American Burlesque at Home and Abroad: Together with the Etymology of Go-Go Girl”, The Journal of Popular Culture, vol. 5, Issue 3, Bowling Green, Bowling Green State University, 1971, p. 565-575.

Fine Gary Alan, "Moral Boundaries, Leisure Activities, and Justifying Fun", in Philip Smith (dir.), The New American Cultural Sociology, Cambridge, Cambridge University Press, 1998, p. 217-229.

Flamiano Dolores, "The (Nearly) Naked Truth: Gender, Race, and Nudity in Life, 1937", Journalism History, vol. 28, n 3, Northridge (CA), Journalism Dept. of California State University, 2002, p. 121-136.

Frank Katherine, "Exploring the Motivations and Fantasies of Strip Club Customers in Relation to Legal Regulations", Archives of Sexual Behavior, vol. 34, n 5, New York, Plenum Press, 2005, p. 487-504.

Grunberger Béla, « De l'image phallique », Revue française de psychanalyse, Tome XxviII, nº 1, Paris, PUF, 1964, p. 217-231.

Hanna Judith Lynne, "Dance under the Censorship Watch", Journal of Arts Management, Law, and Society, vol. 31, n ${ }^{\circ}$, Washington D.C., Heldref Publications, 2002, p. 305-317.

Hansen Clinton P., "To Strip or Not to Strip: The Demise of Nude Dancing and Erotic Expression Through Cumulative Regulations", vol. 35, $\mathrm{n}^{\circ}$ 3, Valparaiso University Law Review, Valparaiso, Valparaiso University School of Law, 2001, p. 561-615. 
LAMBERT Jean-Clarence, « Images choisies d'un Japon sordide et magnifique », ARTS : lettres, spectacles, musique, no 972, Paris, 1964, p. 37-40.

McLelland Mark, "Kissing is a Symbol of Democracy!' Dating, Democracy, and Romance in Occupied Japan, 1945-1952", Journal of the History of Sexuality, vol. 19, $\mathrm{n}^{\circ}$ 3, Austin, University of Texas Press, 2010, p. 508-535.

Sadler A. W., "The Form and Meaning of the Festival", Asian Folklore Studies, vol. 28, nº 1, Nagoya, Nanzan University, 1969, p. 1-16.

Senelick Laurence, "The Word Made Flesh: Staging Pornography in EighteenthCentury Paris", Theatre Research International, vol. 33, n 2, Cambridge U.K., Cambridge University Press, 2008, p. 191-203.

\section{Articles de presse}

« La vertu au Sénat : où le sénateur Béranger venge la morale », Le Matin: derniers télégrammes de la nuit, $\mathrm{n}^{\circ} 3308$, Paris, mardi 21 mars 1893, p. 1.

« Tribunal correctionnel de la Seine : les poursuites du parquet, outrage public à la pudeur, la ligue contre la licence des rues », Le Matin: derniers télégrammes de la nuit, $\mathrm{n}^{\circ} 3403$, Paris, samedi 24 juin 1893, p. 4.

“Japan: Occupational Hazards", Time, 12 juin 1950, en ligne (lien valide au 13 janvier 2011) : http://www.time.com/time/magazine/article/0,9171,812657,00. html.

"So This Is Burulesku", GALA - America's Greatest Array of Glamor, vol. 15, n 1 , New York, Gala Magazine Corporation, December 1964, p. 46-47.

\section{Autres}

Doudet Caroline, Les Parures de la femme fatale, mémoire de DEA (Sémiologie des interactions culturelles) de l'université de Limoges, sous la direction de Bertrand Westphal, 2001. 
EISEnSCHenk Herbert (réalisateur), Le Nu absolu [film documentaire], Autriche - France : Arte - Vermeer Film/ORF, 2010, 60 min ; diffusé sur Arte le 18 septembre 2011.

Entretiens avec HARA Yoshiichi 原芳市, auteur et photographe spécialiste du striptease, les 6 mars et 26 octobre 2012, à Tōkyō.

Entretien avec Yves Riguet, Président d'honneur de Cervin/l'Arsoie (bas et collants) et historien du Crazy Horse, le 13 septembre 2011, à Paris.

Flanigan's Enterprises, Inc. of Georgia, d.b.a. Mardi Gras, Plaintiff-Appellant, v. Fulton County, Georgia, The Board of Commissioners of Fulton County, Georgia, et al., Defendants-Appellees (United States Court of Appeals for the Eleventh Circuit, No. 00-11152). [LexisNexis, réf. : Flanigan's Enters. v. Fulton County, 2001 U.S. App. LEXIS 2418]

Fuller Ron (Capt.), Miller Sue (Lt.), Fulton County Police - Study of Calls for Service to Adult Entertainment Establishments Which Serve Alcoholic Beverages (January 1995 - May 1997), 1997 (Rapport de la police du comté de Fulton, Géorgie).

Kumashiro Tatsumi 神代辰巳, Sayuri strip-teaseuse (titre original : Ichijō Sayuri - Nureta yokujō一条さゆり一濡れた欲情 [Ichijō Sayuri : désirs humides]), Cinémalta, 2009, 69 min.

Waseda daigaku - Engeki hakubutsukan - Dejitaru ākaibu korekushon 早稲 田大学 演劇博物館 デジタルーアーカイブーコレクション (The Tsubouchi Memorial Theater Museum Digital Archives Collection of Waseda University), en ligne (lien valide au 16 janvier 2015) : http://www.enpaku. waseda.ac.jp/db/.

Résumé : La nudité est un phénomène culturel. S'il existait indiscutablement des corps nus au Japon avant la défaite, c'est pendant l'occupation américaine que virent le jour des spectacles exploitant la nudité féminine. L'analyse des 
formes concrètes de ces performances et de leurs évolutions permet de dégager trois périodes distinctes. L'après-guerre connaît une diffusion massive de représentations visant à érotiser le corps féminin. Dès 1947, l'insertion de « nus » sous forme de tableaux vivants dans les spectacles de revue se multiplie. C'est néanmoins à la charnière des années 1950 que la pratique se généralise avec l'apparition, à Asakusa notamment, de théâtres consacrés au striptease. Ces établissements conduisent à un « âge d'or » de l'effeuillage marqué par une inventivité, des innovations scéniques pétulantes et la consécration de vedettes. Amorcée dans les années 1960, la troisième période est quant à elle caractérisée par une intensification du contenu sexuel des performances.

Mots-clés : striptease, nudité, tableau vivant, sex show, Asakusa, érotisme, culture populaire, Shōwa

Abstract: Nudity is a cultural phenomenon. If nude bodies were displayed before 1945, shows and entertainment exploiting female nudity as such only appeared under the American Occupation. The analysis of actual and concrete forms of such performances and their evolutions brings out three distinct periods. During the postwar period, representations eroticizing the female body spread widely. From 1947, the displaying of nudity, in the form of tableau vivant, increased in revue shows. It is around the turn of the 1950s that this kind of practice became widespread, with the appearance of theaters devoted to strip shows, especially in Asakusa. These institutions led to a "golden age" of striptease characterized byunbridled creativity, scenic innovations and the establishment of a star-system. Initiated in the 1960s, the third period is marked by an intensification of the sexual content and aspects of the performances.

Keywords: Striptease, Nudity, tableau vivant, Sex Show, Asakusa, Eroticism, Popular Culture, Shōwa

キーワード：ストリップ, 裸体, 額縁ショ一, 特出し, 浅草, エロチシ ズム, 大衆文化, 昭和 
